\title{
Validation of stochastic ground motion model modification by comparison to seismic demand of recorded ground motions
}

\author{
Alexandra Tsioulou, ${ }^{\text {a) }}$, Alexandros A. Taflanidis, ${ }^{\text {b) }}$ and Carmine Galasso ${ }^{\text {a) }}$
}

An important consideration for the adoption of stochastic ground motion models in performance-based earthquake engineering applications is that the probability distribution of target intensity measures (IMs) from the developed suites of time-histories is compatible with the prescribed hazard at the site and structure of interest. The authors have recently developed a computationally efficient framework to modify existing stochastic ground motion models to facilitate such a compatibility. This paper extends this effort through a validation study by comparing the seismic demand of recorded ground motions to the demand of stochastic ground motion models established through the proposed modification. Suites of recorded and stochastic ground motions, whose spectral acceleration statistics match the mean and variance of target spectra within a period range of interest, are utilized as input to perform response history analysis of inelastic single-degreeof-freedom (SDoF) case-study systems. SDoF systems with peak-oriented hysteretic behavior, strain hardening, and (potentially) degrading characteristics, experiencing different degree of inelastic response are considered. Response is evaluated using the peak inelastic displacement and the hysteretic energy given by the work of the SDoF restoring force as engineering demand parameters (EDPs). The resultant EDP distributions are compared to assess the effect of (and validate) the proposed modification. It is shown that the proposed modification of stochastic ground motion models can provide results that are similar to these from recorded ground motion suites, improving any (in some cases large) discrepancies that exist for the initial, unmodified stochastic ground motion model.

Keywords: Stochastic ground motions, Ground motion records, Spectrum compatibility, Hazard

\section{Introduction}

Performance-based earthquake engineering (PBEE) uses response history analysis (RHA) as a tool to quantify the expected seismic performance of a structure (Moehle and Deierlein 2004; Goulet et al. 2007). Such analysis requires as input ground motion acceleration time-histories (or simply ground motions) that are consistent with the seismic hazard at a given site for each examined structure. This has increased the relevance of ground motion modelling techniques in earthquake engineering. Selection and scaling of recorded ground motions based on target intensity measures (IMs) is undoubtedly the most commonly used approach for such a modeling (e.g., Lin et al. 2013, Kohrangi et al. 2017; Katsanos and Sextos 2018). An IM commonly used in PBEE is the spectral acceleration at a given period $T_{i}$ (for instance, the fundamental period of the considered

\footnotetext{
a) Civil, Environmental \& Geomatic Engineering Department, University College London, London, WC1E 6BT

b) Civil \& Environmental Engineering \& Earth Sciences Department, University of Notre Dame, IN 46556, a.taflanidis@nd.edu, 574-631-5696
} 
structural system), denoted herein as $S_{\alpha}\left(T_{i}\right)$. Ground motion records are selected, and scaled if necessary, so that they are compatible with target $S_{\alpha}(T)$ values over a range of periods around $T_{i}$; for example this is the practice recommended in scenario-based seismic risk assessment (FEMA-P-58 2012) with Ground Motion Prediction Equations (GMPEs) typically utilized to define the target IMs.

An alternative approach for ground motion modelling that has been receiving increasing interest during the past decade is the use of simulated ground motions derived by stochastic ground motion models (e.g., Boore 2003, Rezaeian and Der Kiureghian 2010, Vlachos et al 2018). These models are able to produce acceleration time-histories by modulating a white-noise sequence through functions that address spectral and temporal features of the ground shaking. The parameters of the frequency and time domain functions are related to seismicity (e.g., moment magnitude and rupture-to-structure distance) and site characteristics (e.g., shear wave velocity for soil profile) through predictive relationships. These relationships are traditionally developed through physics-based principles or by matching features of recorded ground motions for specific regions. They are the essential component for the use of stochastic ground motion models for practical applications, relating seismicity characteristics to properties of the ground motion model itself. It is worth noting that another category of simulated ground motions is the physics-based ground motion simulations (Graves and Pitarka 2010; Graves et al. 2011; Anderson 2014). These ground motion simulations are derived by models that explicitly incorporate the physics of the fault rupture, seismic wave propagation, and local site effects, and can be used for future predictions, especially when there is a lack of ground motion records (Mavroeidis and Scotti 2013). Physics-based ground motion simulation methods have rapidly advanced the last decade due to advances in numerical methods and relevant computing capabilities. However, they are still computationally intensive and require a large number of input seismological parameters about the rupture area and regional velocity model that may not be readily available. This makes physics-based ground motion simulation unfeasible for use by most practicing engineers or for comprehensive risk assessment studies, requiring large number of ground motions (rather than limited ground motions for very specific shaking scenarios). Stochastic ground motion simulations on the other hand, are fast to compute and more practical to use in risk assessment studies. The essential link for this use (Gidaris and Taflanidis 2015) are, as pointed out earlier, the aforementioned predictive relationships for their model parameters.

Current approaches, though, for development of these predictive relationships do not necessarily guarantee that the ground motion model will provide acceleration time-series that are consistent with desired target IMs (e.g, Atkinson and Silva 2000; Rezaeian and Der Kiureghian 2010), something that has raised concerns for their implementation in PBEE settings. This issue has motivated researchers (Scherbaum et al. 2006; Vetter et al. 2016) to examine the selection of the predictive relationships so that match to target IMs is optimized. This approach might produce, though, acceleration time-series with physical properties that are unrealistic when compared to regional observed trends. To address this drawback the authors recently (Tsioulou et al. 2018a; Tsioulou et al. 2018b) developed a computationally efficient framework to modify existing stochastic ground motion models with a dual goal of (a) facilitating compatibility with the target conditional hazard described through any chosen IM while (b) preserving desired trends and correlations in the physical characteristics of the resultant ground acceleration time-series. For a given seismicity scenario, the framework identifies the 
modified predictive relationships of the stochastic ground motion model that can sufficiently match the target conditional hazard while maintaining similarity to preexisting predictive relationships, so that observed regional physical characteristics of ground motions are retained. The conditional target hazard is described through the conditional mean and the dispersion of some target IM (Tsioulou et al. 2018b) or simply through only the conditional mean (Tsioulou et al. 2018a). The modification is posed as a multi-objective optimization problem, with different criteria established for selecting the final predictive relationships. This modification may be viewed as having similarities to the popular scaling of recorded ground motions (Katsanos et al. 2010); simply in this instance rather than controlling (as in scaling) only the intensity of the ground motion, which corresponds to only one parameter within the ground motion model, all parameters are modified. The degree of modification across the different parameters is balanced so that to achieve the smallest deviation from the original predictive relationships while providing the desired IM match. The IM and hazard-compatible stochastic ground motions established from the proposed approach should be considered suited for either design of new or assessment of the performance of existing structures (code-based or performance-based assessment, respectively), in the same way that scaled recorded ground motions may be utilized.

This paper extends the previous efforts of the authors through a validation study by comparing the seismic demand of hazard-compatible recorded ground motions to the demands of stochastic ground motion models that are modified to match the same target hazard. Suites of recorded and stochastic ground motions, whose spectral acceleration statistics match the mean and variance of target spectra within a period range of interest, are utilized as input to perform response history analysis of inelastic single-degree-of-freedom (SDoF) casestudy systems. The resultant engineering demand parameters distributions are then compared to perform the desired validation. Validation extends to different seismicity scenarios and different inelastic and hysteretic characteristics for the SDoF systems.

\section{Stochastic ground motion model and proposed modification}

The stochastic ground motion model considered (and modified) is the one developed by Rezaeian and Der Kiureghian (2010), which combines a time-domain modulating envelope function with a frequency-spectrum with time varying spectral properties. It addresses both temporal and spectral non-stationarities and has been shown (Vetter and Taflanidis 2014) to capture essential features observed in response of structures to recorded ground motions, such as moving resonance effects due to interaction between surface seismic waves and the period elongation of inelastic structures (Beck and Papadimitriou 1993). The parameter vector for this model, denoted as $\boldsymbol{\theta}$ herein, consists of: the parameters of the envelope function, corresponding to the Arias intensity $I_{a}$, the significant duration $D_{5-95}$, and the time at the middle of the strong-shaking phase $t_{\text {mid }}$; and the parameters of the frequency-spectrum, corresponding to the damping ratio $\zeta_{f}$, the spectral frequency $\omega_{\text {mid }}$ at $t_{\text {mid }}$, and the rate of change for that frequency $\omega$ ' (linear variation is assumed for the spectral frequency). The first parameter $I_{a}$ determines the intensity of the ground motion (corresponds to a scaling parameter), while the remaining five dictate the temporal and spectral variation characteristics. The model parameter vector $\boldsymbol{\theta}$ is related through predictive relationships to seismicity and local site parameters: the moment magnitude, $M$, the rupture distance, $r_{r u p}$, the fault type, $F$, and the shear wave velocity in the upper 30 meters of soil, $V_{s 30}$. The vector of these four 
parameters is denoted as $\mathbf{z}$ herein. The predictive relationships developed by Rezaeian and Der Kiureghian (2010) ultimately define a conditional probability distribution that relates $\boldsymbol{\theta}$ to $\mathbf{z}$, denoted herein as $p\left(\boldsymbol{\theta} \mid \boldsymbol{\mu}_{r}(\mathbf{z}), \boldsymbol{\Sigma}_{r}\right)$, where $\boldsymbol{\mu}_{r}(\mathbf{z})$ are the mean predictions and $\boldsymbol{\Sigma}_{r}$ represents the variability of these predictions. Note that characteristics $\boldsymbol{\mu}_{r}(\mathbf{z})$ and $\boldsymbol{\Sigma}_{r}$ pertain to the transformed to standard Gaussian space model parameters and represent, respectively the mean vector and the covariance matrix. This ground motion model description ultimately provides a probabilistic prediction for any IM of interest, with variability in the predictions stemming from both (i) the stochastic characteristics of the ground motion model (i.e., fact that it entails a white noise sequence); and (ii) the probabilistic description of the predictive relationship between $\mathbf{z}$ and $\boldsymbol{\theta}$ (i.e., the fact that $\boldsymbol{\Sigma}_{r}$ exists). For spectral acceleration at a given period $T_{i}$, which is the IM utilized in this paper, the probabilistic description through the ground motion model is denoted as $p_{g}\left(\ln \left(S_{a}\left(T_{i}\right)\right) \mid \boldsymbol{\mu}_{r}(\mathbf{z}), \boldsymbol{\Sigma}_{r}\right)$ and, as shown in (Tsioulou et al. 2018b), can be approximated very well as a lognormal distribution utilizing simply the median and dispersion [under the aforementioned two sources of variability (i-ii)] of $S_{a}\left(T_{i}\right)$. A complete mathematical description of all these statistics is available in (Tsioulou et al. 2018b) and is briefly reviewed in Appendix A.

The modification framework developed by the authors (Tsioulou et al. 2018b) adjusts $\boldsymbol{\mu}_{r}(\mathbf{z})$ and $\boldsymbol{\Sigma}_{r}$ (replaces them with $\boldsymbol{\mu}$ and $\boldsymbol{\Sigma}$, respectively) for each examined $\mathbf{z}$ so that the conditional (to the seismicity scenario defined by $\mathbf{z})$ seismic hazard established through the modified model, $p_{g}\left(\ln \left(S_{a}\left(T_{i}\right)\right) \mid \boldsymbol{\mu}, \boldsymbol{\Sigma}\right)$, provides a closer match to the desired target seismic hazard for the IM, $p_{t}\left(\ln \left(S_{a}\left(T_{i}\right) \mid \mathbf{z}\right)\right.$. In the context of this study, the latter is determined through GMPE predictions for the median and dispersion of $S_{a}\left(T_{i}\right)$ considering a range of periods $T_{i}$. This ultimately facilitates a GMPE-based (or scenario-based) spectra compatibility of the modified stochastic ground motion model. This modification is expressed as a multi-objective optimization problem, briefly reviewed in Appendix A, with two competing objectives. The first objective, $F_{1}$, is to minimize the discrepancy of the target seismic hazard to the hazard predicted through the ground motion model, i.e. to a comparison between $p_{g}\left(\ln \left(S_{a}\left(T_{i}\right)\right) \mid \boldsymbol{\mu}, \boldsymbol{\Sigma}\right)$ and $p_{t}\left(\ln \left(S_{a}\left(T_{i}\right) \mid \mathbf{z}\right)\right.$. The second objective, $F_{2}$, is to establish the smallest deviation between the updated probability model $p(\boldsymbol{\theta} \mid \boldsymbol{\mu}, \boldsymbol{\Sigma})$ and the initial predictive relationships $p\left(\boldsymbol{\theta} \mid \boldsymbol{\mu}_{r}(\mathbf{z}), \boldsymbol{\Sigma}_{r}\right)$, so that consistency of the physical characteristics of the resultant ground motion simulations with the regional trends observed in recorded ground motions is achieved. The relative entropy is utilized to quantify both these objectives, corresponding ultimately to the difference between probability distributions, and a computational framework relying on surrogate modelling (Tsioulou et al. 2018b) is leveraged to efficiently solve the resultant multi-objective optimization. A simplified implementation of this framework also exists (Tsioulou et al. 2018a) that completely ignores variability in the predictive relationships, i.e. enforces $\boldsymbol{\Sigma}=\boldsymbol{\Sigma}_{r}=\mathbf{0}$ (variability stemming from stochastic features of ground motion model still considered), and establishes compatibility with respect to the median IM predictions, rather than the complete hazard (median and dispersion of predictions). This simplified version yields significantly higher computational efficiency (Tsioulou et al. $2018 b$ ) with the caveat, of course, that the dispersion of the predictions is not explicitly optimized. Objective $F_{1}$ is expressed in this case as the average squared relative error for $S_{a}\left(T_{i}\right)$ between the ground motion predictions and the GMPE-target across the considered periods, whereas objective $F_{2}$ as the weighted squared difference between $\boldsymbol{\mu}$ and $\boldsymbol{\mu}_{r}(\mathbf{z})$. The simplified implementation is references herein as IMC (IM compatibility) 
with the full one referenced as $\mathrm{HC}$ (Hazard compatibility). To establish a complete similarity between objectives $F_{1}$ and $F_{2}$ discussed in papers (Tsioulou et al. 2018a) [IMC case] and (Tsioulou et al. 2018b) [HC case], the objectives from the original paper (Tsioulou et al. 2018a) are scaled in this work by a factor of 1/2; this ultimately stems from the discrepancy between the relative-entropy quantification of the objectives used in (Tsioulou et al. 2018b) [which includes scaling by 1/2] to the mean error used in (Tsioulou et al. 2018a) [which does not include such a scaling]. Further details about these ground motion modifications approaches are provided in Appendix A.

The solution of the associated multi-objective optimization problem for either case leads to a Pareto set of dominant solutions expressing a different compromise between the two competing objectives. The representation of the Pareto set in the performance objective $\left[F_{1}, F_{2}\right]$ space, is termed as the Pareto front. For better comparative normalization of the solutions the front is represented through the square root of the objectives $\left[\sqrt{F_{1}}, \sqrt{F_{2}}\right]$ (Tsioulou et al. 2018a; Tsioulou et al. 2018b). Figure 1 shows representative Pareto fronts for all seismicity scenarios discussed later in this paper. The front ranges from the unmodified model, denoted $U_{n}$ herein, corresponding to $F_{2}=0$ and higher discrepancy from the IM-target (larger $F_{1}$ values), to models that establish high compatibility to the IM-target (small $F_{1}$ values) at the expense of significant deviation of the model characteristics from the initial predictive relationships (large $F_{2}$ values). Further reduction of $F_{1}$ (ultimately achieving $F_{1}=0$ ) is achieved by deviation from the initial predictive relationships that might yield unrealistic characteristics for the resultant ground motions and this part of the front is not identified through the use of appropriate constraints in the multi-objective optimization (Tsioulou et al. 2018b). One can eventually select a model configuration from the identified Pareto set that yields the desired hazard compatibility (or strictly IM compatibility for IMC) based on objective $F_{1}$ without deviating significantly from regional ground motion characteristics based on objective $F_{2}$. Following recommendations in (Tsioulou et al. 2018a; Tsioulou et al. 2018b), three specific points are examined, also shown in Figure 1. The first one, denoted $U_{t}$, is the point with minimum distance from the Utopia point, corresponding to the minimum of the two objectives across the Pareto front (this performance is unachievable due to the conflicting nature of the objectives). $U_{t}$ offers a balanced compromise between the competing objectives and, as shown also in Figure 1 , improvement of one objective is typically established away from that point with greater sacrifices in the other objective (front has steep slope). The other two chosen points are defined as the ones that achieve a predetermined compatibility with respect to target hazard, i.e. a specific threshold value of objective $F_{1}$. The first of these points, denoted $C_{s}$, corresponds to high compatibility (small $F_{1}$ threshold), whereas the second point, denoted $C_{l}$, is defined following the multi-level criterion proposed by Tsioulou et al. (2018a, 2018b): select the point that provides a moderate compatibility (larger threshold for $F_{1}$ compared to $C_{s}$ ) unless that point provides a smaller compatibility to the target than $U_{t}$; for those instances update $C_{l}=U_{t}$. This update avoids defining a $C_{l}$ point that belongs to the steep part of the Pareto front with respect to objective $F_{2}$ (Tsioulou et al. 2018a; Tsioulou et al. 2018b), and is explicitly denoted herein though use of $C_{l}=U_{t}$ symbolic terminology. Also for the $C_{s}$ case, if no point in the Pareto front satisfies the desired threshold, the extreme of the front with respect to $F_{1}$ is used instead. The thresholds for $\sqrt{F_{1}}$ defining $C_{s}$ and $C_{l}$ points are taken as 0.014 and 0.05 for 
the IMC and $\mathrm{HC}$ cases, respectively, for $C_{s}$ and 0.07 and 0.15 for the IMC and $\mathrm{HC}$ cases, respectively, for $C_{l}$. These thresholds are chosen to represent moderate and high compatibility for $C_{l}$ and $C_{s}$ respectively based on the features of objective $F_{1}$ for each of the cases examined. Studies (Tsioulou et al. 2018a) and (Tsioulou et al. 2018b) offer greater insights for this selection for the two cases, respectively.

Each of the models corresponding to these three modifications $\left(U_{t}, C_{s}\right.$ and $\left.C_{l}\right)$ or the unmodified model $\left(U_{n}\right)$ represents a different stochastic ground motion model, always for the specific scenario defined by the vector $\mathbf{z}$. For the IMC case, each model corresponds to a single set of ground motion model parameters since variability in the predictive model for $\boldsymbol{\theta}$ is ignored. Synthetic acceleration time-histories are obtained by utilizing different white-noise sequence samples each time, using always the same model parameter vector. For the HC case, a complete probabilistic description is established for $\boldsymbol{\theta}$. Synthetic acceleration time-histories are obtained by utilizing different white-noise sequence samples along with different model parameter samples drawn from this probabilistic description.

\section{Characteristics for validation study}

\subsection{Seismicity scenarios and target IM description}

As in similar past studies (Iervolino et al. 2010a; Galasso et al. 2012; Seifried and Baker 2016), the validation of the stochastic ground motion modification approach discussed in the previous section is performed for specific seismicity scenarios. Six different scenarios are selected, corresponding to combination of moment magnitude values $M=[6,6.9,7.8]$ and rupture distance values $r_{r u p}=[20,70] \mathrm{km}$ for a strike-slip fault, with shear wave velocity $V_{s, 30}=600 \mathrm{~m} / \mathrm{s}$. Note that these are the four characteristics needed to define the stochastic ground motion model input (vector $\mathbf{z}$ ). For the remainder of this paper seismicity scenarios with $M=[6,6.9,7.8]$ and $r_{r u p}=20 \mathrm{~km}$ are referred to as Scenarios 1,2 and 3, respectively, and scenarios with $M=[6$, $6.9,7.8]$ and $r_{\text {rup }}=70 \mathrm{~km}$ as Scenarios 4,5 and 6, respectively. As target IMs, $S_{a}\left(T_{i}\right)$ in the period range $0.2 T_{1^{-}}$ $1.5 T_{1}$ are utilized, where $T_{1}$ is the fundamental period of the structure. An elastic period of $T_{1}=1 \mathrm{~s}$ is selected, which is typically used as representative fundamental period of mid-rise buildings. Note that the aforementioned period range is chosen based on (ASCE 2010) provisions and recent literature recommendations (Katsanos and Sextos 2015). Establishing a match in the period range below $1 \mathrm{~s}$ will not have any impact on the results because higher modes do not contribute to the SDOF system response, however, the match was established in this range for code consistency. This choice for the IM definition follows standards adopted in many similar studies (Iervolino et al. 2010a; Galasso and Iervolino 2011) though evidently the results of the validation study are somewhat impacted by this selection. The median and dispersion for the target IMs are given for each $T_{i}$ as the average of four GMPEs used in the Western US, namely the ones by Campbell and Bozorgnia, Abrahamson and Silva, Boore and Atkinson, and Chiou and Youngs (Abrahamson et al. 2008; Power et al. 2008). Note that this is simply chosen for consistency with previous work of the authors; any other GMPEs, or any other approach that would define an IM description to match (Bradley 2010; Lin et al. 2013), could have been used instead. The suggestions by Kaklamanos et al. (2011) are adopted to estimate unknown inputs for some of the GMPEs that need info beyond $M, r_{r u p}, V_{s 30}$ and fault type. For each of the seismicity scenarios the stochastic ground motion model modification is 
implemented as outlined in the previous section, resulting in the Pareto fronts presented in Figure 1. For the $U_{n}, U_{t}, C_{s}$ and $C_{l}$ models, 200 synthetic acceleration time-histories are then obtained for the IMC and $\mathrm{HC}$ cases to be used as input for RHA. Should be pointed out that the initial (unmodified) model established by Rezaeian and Der Kiureghian (2010) was developed strictly from the perspective of a HC implementation, with predictive models for $\boldsymbol{\theta}$ established explicitly considering the associated variability. Still $U_{n}$ is examined in both IMC and HC cases here, to demonstrate the benefits of the stochastic ground motion model modification.

\subsection{Recorded ground motions}

The ground motion record set that is utilized as reference in the study, denoted as $S R$ herein, is selected using REXEL (Iervolino et al. 2010b), a software that is freely available at http://www.reluis.it/ and allows users to select records from the European Strong Motion Database (or ESD, http://www.isesd.hi.is/), the Italian Accelerometric Archive (or ITACA, http://itaca.mi.ingv.it/ItacaNet/), and the Selected Input Motions for Displacement-Based Assessment and Design database (or SIMBAD database, (Smerzini et al. 2014). The selected records match on average a code-based or user-defined elastic spectrum in a desired period range and with specified upper and lower bound tolerances. REXEL is able to identify ground motions with desired seismicity and site characteristics (in terms of magnitude, source-to-site distance, and soil profile), which is the reason preferred for this study, as the identified reference ground motions need to have physical properties consistent with the seismicity scenario examined. For each of these six scenarios, a reference set of 30 ground motion records from the SIMBAD databases was selected matching the median GMPE predictions discussed in the previous section in period range $0.2 T_{1}-1.5 T_{1}$ with a deviation from the target of $\pm 20 \%$. Records are reported in Appendix B. The choice of the number of records (30) is mainly based on the state-of-the-practice as well as computational demand and record availability constraints. For instance, (FEMA-P-58 2012) recommends in its Sec. 6.2.4 a number of ground motions on the order of 20 to "obtain reliable estimates of collapse fragility"; other standards usually recommend to use a minimum number of ground motions on the order of seven (CEN 2004; ASCE 2010) to eleven (ASCE 2016), to accurately describe the mean structural response from nonlinear RHA. Reyes and Kalkan (2012), among others, statistically investigated the required number of records for code-based seismic demand assessment of case-study inelastic SDoF (as in this study). The study concluded that utilizing seven or more randomly selected records provides accurate estimate of the responses (in terms of mean value and dispersion uncertainty), especially when records are selected based on their spectral shape (as in this study).

It is worth noting that most of the chosen ground motions also belong to the NGA database (Chiou et al. 2008); this is important since the stochastic ground motion model considered here was calibrated against that database (Rezaeian and Der Kiureghian 2010). Therefore, a consistent comparison is established between the recorded and stochastic ground motions utilized. The average values of magnitude and distance of the chosen records were [6, 21km] for Scenario 1, [6.9, 22km] for Scenario 2, [7.1, 24km] for Scenario 3, [5.9, 66km] for Scenario 4, $[6.9,70 \mathrm{~km}]$ for Scenario 5 , and $[7.5,79 \mathrm{~km}]$ for Scenario 6. For the high-magnitude cases the constraint on $M$ was relaxed as it was not possible to identify the desired large number of ground motion records with the specific seismicity characteristics (lack of large magnitude records in the database). A uniform 
scaling was applied to all the records so that they match exactly the IM target for the fundamental period $T_{1}=1$ s. This was done so that for the elastic SDoF response examined later, the reference case is identical to the set target, since $S R$ is taken as the benchmark reference for the RHA (it is therefore reasonable to expect match to the target IM for elastic response). Given the relatively small deviation of the selected records from the target, this uniform scaling was in most cases small.

\subsection{SDoF system characteristics and demand measures}

The validation study is performed for a number of inelastic SDoF systems with peak-oriented hysteretic behavior, strain hardening, and (potentially) degrading characteristics as shown in Figure 2. The initial (elastic) SDoF stiffness $k_{e l}$ is determined based on the fundamental period $T_{1}$ of $1 \mathrm{~s}$ whereas a constant massproportional viscous damping coefficient corresponding to a 5\% critical damping ratio (based on elastic stiffness characteristics) is used. With respect to the characteristics of the inelastic behavior, the following variations are considered to establish a comprehensive validation setting:

- Strength reduction factors $(R)$. The yield strength, $F_{y}$, is chosen based on the elastic demand of the SDoF system through $R$, defined as the ratio of elastic base shear demand (peak elastic restoring force) to $F_{y}$. Different values of $R$ are considered to describe structural behavior ranging from mildly inelastic ( $R=2$ and 4$)$ to severely inelastic structures ( $R=6$ and 8$)$. The linear behavior $\left(F_{y}=\infty\right)$ is also considered in this study and, for unification of presentation, it will be frequently referenced as $R=1$.

- Hysteretic behavior. Two different systems are examined, a non-degrading one (Figure 2a), and a degrading one (Figure 2b), referenced herein as EPH and ESD, respectively. Both of them have a strain hardening branch post-yield defined through the ratio $a$, and a peak-oriented hysteretic behavior. The ESD system has an additional softening branch after the displacement $\Delta_{u}$ defined through the ratio $\beta$, and a residual strength of $\gamma F_{y}$. For the EPH system, two different values of $a$ will be examined: 3\% and 10\%. For the ESD system, $a$ and $\beta$ are taken to be 3\% and 5\%, respectively, with value of $\gamma$ taken as $10 \%$ (all correspond to common values appearing in literature). The displacement for the onset of deterioration, $\Delta_{u}$, is chosen to be proportional to the yield displacement, $\Delta_{y}$, and the strength reduction factor $R$, i.e., $\Delta_{u}=R \cdot \Delta_{y}$. This leads to higher ductility to systems with higher $R$ value, an assumption aligned with current design codes.

For determining the elastic base shear demand, and therefore the values for $R$ and $F_{y}$, two different approaches are adopted: (a) achieve the same value of $R$ for each record examined; or (b) achieve the same value of $F_{y}$ for each seismicity scenario so that the desired value of $R$ is obtained in an average sense for the records in the corresponding dataset. Approach (a) will be denoted herein as "constant- $R$ " and approach (b) as “constant-strength". For the "constant- $R$ " approach, the yielding strength of the structure $F_{y}$ varies, ultimately, from record to record. For each record, the peak elastic base shear, $F_{e l}$, is first calculated assuming linear behavior (denoted herein as $R=1$ ) and then, for each $R$ value examined, the yield force is set to $F_{y}=F_{e l} / R$. This “constant- $R$ " approach guarantees a similar degree of nonlinearity per examined record (same $R$ value), directly addressing the variability between ground motions by appropriately scaling SDoF strength for each of them. The "constant-strength" approach on the other hand, examines the behavior of SDoF structures with the same characteristics (same strength) across all examined records and therefore corresponds to the implementation 
that better represents practical applications (e.g., based on current codes and standards). Strength $F_{y}$ for each seismicity scenario is chosen based on the median IM target for that scenario, $S_{a t}\left(T_{1}\right)$, as $F_{y}=m S_{a t}\left(T_{1}\right) / R$, where $m$ corresponds to the SDoF mass. This implementation ultimately takes the median IM target to represent the design earthquake for that Scenario and designs the SDoF structure according to that earthquake. Rather than the same $R$ for each ground motion record, this approach enforces the target $R$ on average across each examined dataset while adjusting for deviations from design demand $S_{a t}\left(T_{1}\right)$; ultimately the average strength reduction factor achieved is $R S_{a m}\left(T_{1}\right) / S_{a t}\left(T_{1}\right)$ where $S_{a m}\left(T_{1}\right)$ is the average $S_{a}\left(T_{1}\right)$ for the dataset. As discussed above, this implementation better represents practical applications: same SDoF structure with characteristics designed for each Scenario based on the design event for that Scenario. Note, also, that elastic behavior for constant-strength approach does not correspond to $R=1$, since $R=1$ will lead to yielding for excitations for which $S_{a t}\left(T_{1}\right)$ is above the target $S_{a m}\left(T_{1}\right)$ based on strength definition $F_{y}=m S_{a t}\left(T_{1}\right) / R$, but for uniformity of presentation of results across both approaches the elastic case will be still denoted as $R=1$ herein. The combination of type of hysteretic SDoF behavior and $R$ values examined cover both steel and concrete structures, ranging from modern code-conforming systems (higher $R$ values) to older systems (lower $R$ values).

Two different engineering demand parameters (EDPs) are used as representations of SDoF response: peak inelastic displacement, $\Delta_{i n}$, and the hysteretic energy, $E_{H}$, given by the work of the SDoF restoring force, or equivalently by the area under the restoring force/displacement curve (Figure 2). These parameters are considered in order to investigate, respectively, the peak displacement demand and the cyclic behavior as also done in past SDoF studies (Iervolino et al. 2010a; Galasso et al. 2012). $E_{H}$ will be presented normalized by SDoF mass $m$. For performing the nonlinear response history analysis of the SDoF the SIMULINK modeling environment was used (Mathworks 2018), following the guidelines in (Gidaris and Taflanidis 2013) for computational efficient implementation.

\section{Comparison of synthetic and recorded ground motions to target spectra}

Before discussing the validation study in terms of inelastic structural response, the elastic spectra for the synthetic and recorded ground motions are first presented and compared in this Section. Figure 3 shows the average spectral estimates from the suite of recorded $S R$ and stochastic (synthetic) ground motions corresponding to models $U_{n}, U_{t}, C_{s}$ and $C_{l}$ for the IMC case and for all six Scenarios. The target spectra are also shown. For the $S R$ case statistics are shown for the motions obtained directly from REXEL, without the scaling that was utilized to create the reference ground motion set. Figure 4 presents the results for the HC case. Figure 5, finally, presents the dispersion of the spectral estimates for all implementations examined, covering both the IMC and HC cases for the stochastic ground motion models.

The recorded $S R$ ground motions have high compatibility with the target (Figures 3,4) something attributed to the use of small tolerance $(20 \%)$ and the fact that the constraints on seismicity characteristics were relaxed for some of the Scenarios in order to satisfy this tolerance. The REXEL optimization routine exploited this relaxation to provide suites of ground motions with small discrepancy from the target. The dispersion (Figure 5) of the stochastic ground motions for the IMC case is much lower than the target as expected because only 
the white noise is contributing to the observed dispersion in this case. On the other hand, the HC stochastic ground motions have a higher dispersion that is comparable to the target. The stochastic ground motion model modification achieves a better match to the target dispersion compared to the unmodified model case. Finally, the dispersion of the recorded ground motions (SR) is higher than that of IMC modifications and, for some scenarios, reaches or exceeds the target. Any discrepancies from the target are justifiable since the REXEL optimization only tries to match the target spectrum through the selection of ground motions and not, additionally, the dispersion of these ground motions (which is only indirectly controlled through the chosen tolerances).

For the stochastic ground motion suites, the results agree with the ones presented earlier in Figure 1 with respect to the discrepancy from the target ( $F_{1}$ values). The unmodified model, $U_{n}$, does not provide a good match to the desired target for some seismicity Scenarios, overpredicting the resultant spectral acceleration values for small $M$ values and underpredicting them for large $M$ values. Note that this trend agrees with the results reported by Rezaeian and Der Kiureghian (2010) when comparing their model to some of the GMPEs utilized here. The HC case (Figure 4) provides better match than the IMC case (Figure 3 ) for $U_{n}$, which should be expected since, as also commented earlier, the predictive models were developed by Rezaeian and Der Kiureghian (2010) assuming a HC implementation. The proposed modification ( $U_{t}, C_{s}$ and $C_{l}$ models) now, facilitates in all instances an improved match for both the IMC (Figure 3) and the HC cases (Figure 4) with $C_{s}$ achieving in all instances very high compatibility, even better than $S R$. This further validates the ability of the modification framework proposed by Tsioulou et al. (2018a, 2018b) in facilitating an improved match to a target IM. With respect to the dispersion (Figure 5), all IMC models significantly underestimate the target variability. This is attributed to the fact that the only source of variability for the response stems from the stochastic nature (white-noise sequence) of the models since the variability in the predictive relationship for $\boldsymbol{\theta}$ is ignored. This leads to smaller response dispersion compared to the one observed in the recorded ground motions, and corresponds to an important shortcoming of the IMC modification approach (Tsioulou et al. 2018b) when that dispersion is also of importance (e.g., when assessing collapse risk due to more extreme ground motion records). The $\mathrm{HC}$ case, on the other hand, can explicitly control this dispersion through adjustment of $\boldsymbol{\Sigma}$ in the predictive relationships, and as evident from Figure 5, high compatibility is achieved for the modified models $U_{t}, C_{s}$ and $C_{l}$ improving upon the unmodified one $U_{n}$.

\section{Comparison of inelastic demand for "Constant-R" approach}

Focus is shifted next to the validation study in terms of structural response. For each seismicity Scenario, the suites of recorded and simulated ground motions are used as input to the different SDoF systems to perform nonlinear RHA. For each considered system and EDP, $\Delta_{i n}$ and $E_{H}$, the statistics, namely median and coefficient of variation $(\mathrm{CoV})$, are estimated across each suite. Results are reported for different values of $R$ and further distinction is established between EPH and ESD SDoFs. For the synthetic ground motions, results are reported for the IMC and HC cases together in each figure using color pattern black and gray, respectively. To more clearly depict differences with respect to the reference (benchmark) $S R$ results, the relative error between the 
response output for any stochastic ground motion modification case and $S R$ is introduced, calculated for the output statistic $s$ as

$$
\varepsilon(s)=\frac{s(S M)-s(S R)}{s(S R)}
$$

where $s(S M)$ is the output statistic (median or $\mathrm{CoV}$ ) from the simulated ground motions and $s(S R)$ is the same output statistic from the recorded ground motions. Results for the "Constant-R" approach are first discussed in this Section.

Figures 6-11 present results for the EPH system with $a=3 \%$. Figure 6 presents the normalized results for the median $\Delta_{i n}$ estimates, $\bar{\Delta}_{i n}$, while Figure 7 the relative error $\varepsilon\left(\bar{\Delta}_{i n}\right)$. Normalization in Figure 6 is established with respect to the elastic spectral displacement $S_{d}$. Figure 8 presents results for the median hysteretic energy burned $E_{H}, \bar{E}_{H}$, while Figure 9 relative error $\varepsilon\left(\bar{E}_{H}\right)$. Figures 10 and 11 show dispersion results (expressed through the $\mathrm{CoV}$ ) for $\Delta_{i n}$ and $E_{H}$, respectively. For these, and all remaining figures, the cases where $C_{l}=U_{t}$ is not explicitly denoted (as was done in previous figures); simply $C_{l}$ is not reported for these instances, corresponding to Scenarios 1 and 3-6 for IMC and Scenarios 1 and 6 for HC. Also, a horizontal dashed line defining best performance is added in the figures when applicable (this is applicable to all figures reported from this point on); for example this line corresponds to $\overline{\boldsymbol{\Delta}}_{\text {in }} / S_{d}=1$ in Figure 6 of $\varepsilon\left(\overline{\boldsymbol{\Delta}}_{\text {in }}\right)=\varepsilon\left(\bar{E}_{H}\right)=0$ in Figures 7 and 9.

Results show that the proposed modification facilitates overall a better match to the reference results of the recorded ground motions in terms of median response statistics. Exceptions to this general trend exist only for significant degree of inelastic behavior ( $R$ value equal to 8$)$ and for scenarios for which the unmodified model provides a good match to the (elastic) target hazard to start with (Scenarios 2 and 5). In those instances, the unmodified ground motion model has a better match to the $S R$ statistics. Note, though, that the error of the proposed modification in these instances is still small. Overall the absolute error of all the modified ground motion models stays consistently below 40\%-50\% (and in most instances in range of 20\%-30\%), with exception of large values of $R$ for Scenario 6. This is not true for the unmodified model which has errors exceeding $100 \%$ in some instances. The modification also contributes to smaller sensitivity of the behavior across the different examined scenarios; even though great variability is observed for the unmodified model $U_{n}$ across the different scenarios, this variability is reduced for the results of the modified ground motion models. This variability is small for $R=1$ as expected (since modification matches the target for elastic behavior) and increases as degree of inelastic behavior increases (larger values of $R$ ). For small values of $R$, there is a strong correlation of the results to the $R=1$ case for $\Delta_{i n}$ and therefore to the results reported in Figures 3-4 or the reported $F_{1}$ values in Figure 1. Note that for large values of $R$, the nonlinear structural response is sensitive to spectral ordinates at periods much larger than the fundamental one (e.g., due to period elongation stemming from the strong nonlinear behavior); the chosen period range for spectral compatibility (i.e., $0.2 T_{1^{-}}$ $1.5 T_{1}$ ) may not be conservative in those cases (Katsanos and Sextos 2015), yielding the observed large variability for larger values of $R$. 
In general, the IMC and $\mathrm{HC}$ modification cases yield very similar trends for the median response and similar results apart from some large $R$ value instances for Scenario 3. Comparing the different modification implementations, $C_{s}$ provides overall the smallest errors apart from large values of $R$ for Scenarios 3 and 6. This might lead someone to conclude that the significant alteration of ground motion physical characteristics, established in the $C_{s}$ case, might have an impact when looking at high levels of inelastic behavior. The discrepancies observed could be attributed, though, to the fact that $S R$ implementation for these two scenarios led to ground motions with different seismicity characteristics than the targeted $M, r_{r u p}$ values, and therefore, possibly, to different physical characteristics for the ground motions than expected for these scenarios. As such, any discrepancies for large degree of inelastic behavior, that is for the instances these physical characteristics are influential, might not be surprising. Still even for these two scenarios the recommended modification, corresponding to $C_{l}$ (which recall is equal to $U_{t}$ in some instances), yields small errors. All these trends hold for both the peak displacement (Figures 6 and 7) as well as for the hysteretic energy (Figures 8 and 9). This is an important feature as both these EDPs are commonly used to describe performance in earthquake engineering applications (Ruiz-García and Miranda 2003; Deniz et al. 2017).

For the dispersion characteristics (Figures 10 and 11), the variability trends reported in Figure 5 extend to the inelastic behavior. Significant differences exist for this statistic between the IMC and HC applications, as expected, with HC providing enhanced compatibility to the target or reference/benchmark values. This, once more, demonstrates the importance of facilitating hazard compatibility, rather simply IM compatibility (Lin et al. 2013; Tsioulou et al. 2018b). In general, results for most modification implementations are very similar. This should be attributed to the fact that the unmodified model is close to the target dispersion (so small modifications are only required) and the fact that as explained in (Tsioulou et al. 2018b), matching of the median statistics is typically more important than matching dispersion statistics for facilitating the overall hazard compatibility. These facts ultimately contribute to a smaller modification of the dispersion statistics. Variation of $R$ in general does not significantly affect the observed dispersion patterns. For the seismicity scenarios for which the spectral dispersion from records $(S R)$ is close to the target, this dispersion is also close to the dispersion for the HC modification. For other scenarios the differences between $S R$ and the HC modifications remain similar to the differences between $S R$ and the target dispersion, apart from Scenario 2 for which $S R$ itself demonstrates a bit of irregular trend, with significant variation of dispersion across different $R$ values. Overall trends are again consistent for both the peak displacement and the hysteretic energy.

Figure 12 repeats results of Figure 6 but for the EPH system with $\alpha=10 \%$. Results show exceptionally similar patterns indicating little sensitivity to value of $\alpha$ (as long as latter is in reasonable range). Similar pattern holds for the other statistics, not reported here due to space limitations. Focus is placed herein on the $a=3 \%$ case.

Figures 13-15 present results for the ESD system for $\Delta_{i n}$. Results for $E_{H}$ are not presented due to space limitations but are practically identical to the trends observed for EPH with some reduction in the $E_{H}$ values for large $R$ values, due to the reduced energy dissipation capabilities when structure enters softening branch of backbone curve. Differences to the EPH case appear only for the large nonlinearity cases $(R=6$ or 8$)$ since for lower $R$ values system does not move significantly into the softening branch. Discrepancies to the reference 
results are amplified for the ESD model with respect to both the median response (Figures 13-14) as well as dispersion (Figure 15). For the $R=8$ case and for a considerable portion of the simulations (over $10 \%$ for most Scenarios), structure reached residual strength, so high variability and larger discrepancies (Figure 15) can be also attributed to that; once the residual strength is reached the response output is very sensitive to small changes in the ground motion features. For the median statistics, errors are especially amplified for the $C_{l}$ modification, with higher error values reported for many of the examined seismicity scenarios. For the $C_{s}$ modification, on the other hand, these errors remain relatively small for most of the cases examined. For the dispersion statistics the agreement to the reference/benchmark results deteriorates overall.

\section{Comparison of inelastic demand for "Constant-strength" approach}

This Section extends comparison to "Constant-strength" approach. Due to space limitations, only the most informative results are presented in Figures 16-21. For the other cases, trends are very similar to the ones discussed for "Constant-R" approach. Figures 16-18 show results for the EPH system with $\alpha=3 \%$, the relative error $\varepsilon\left(\overline{\boldsymbol{\Delta}}_{i n}\right)$, coefficient of variation for $\Delta_{i n}$ and median hysteretic energy $\bar{E}_{H}$ respectively. Figure 19-21 presents same results for the ESD system. Results for the median displacement (Figures 16 and 19) and hysteretic energy (Figures 18 and 21) response have similar trends to the corresponding cases for constant-R approach, with notable higher error with respect to reference $S R$ for the $U_{n}$, with even higher estimates for Scenarios 1 and 4 and even lower estimates for Scenarios 2, 3, 5 and 6. Notably for Scenario 6 the behavior remains elastic for $R=2$ for $U_{n}$, as evident from the zero values of $\bar{E}_{H}$ (Figures 18 and 21). The differences reported stem from the significant discrepancies to the target for the elastic case (corresponding to $R=1$ in the figures) for $U_{n}$, which contributes to lower or higher strength compared to the benchmark $(S R)$ case for the two groups of Scenarios, respectively. At extremes (Scenario 6) this leads to drastically different behavior than expected (elastic behavior even when design is targeting inelastic response). For the modified stochastic ground motion model, on the other hand, only small differences exist with respect to the "Constant-R" approach, keeping the errors moderately low. This is expected; since the modification leads to a good match to the target ( $R=1$ case), not significant differences are expected between the "Constant- $\mathrm{R}$ " and "Constantstrength" implementations. This further stresses the importance of the proposed modification as it is able to facilitate good match to the benchmark results, compared to the unmodified ground motion model, for the "Constant-strength" implementation which corresponds, as mentioned earlier, to the implementation that is more comparable to practical applications. Finally, results in Figures 17 and 20 show that the "Constantstrength" approach leads to higher dispersion estimates for the peak inelastic displacement ratios for the HC modification and $S R$ cases. A possible reason for this is that the higher variability of the ground motion response in these sets is affected more by the adoption of a constant yield strength that results in higher dispersion estimates for this EDP. Still though, there is a similar level of agreement between HC and $S R$ as in the "Constant-R" approach.

\section{Summary and conclusions}

A validation study for the stochastic ground motion model modification proposed recently by the authors was performed in this paper by comparing the seismic demand for inelastic SDoF systems of hazard- 
compatible recorded ground motions to the demand of stochastic ground motion models that are modified to match the same target hazard. Comparison was performed for two different engineering demand parameters, peak displacement and hysteretic energy, and for SDoF systems with different degrees of inelastic behavior, corresponding to different values of strength reduction factor $R$, and different nonlinear and hysteretic characteristics. For the latter, a peak-oriented hysteresis model was chosen with different values for post-yield stiffness, considering non-degrading (EPH system) or degrading (ESD system) strength characteristics. Six different seismicity scenarios were examined, corresponding to different values of moment magnitude and rupture distance for seismic events. The recorded ground motions were obtained through the REXEL software, while for the modified stochastic ground motion model, different modification degrees were examined.

Results show that the proposed modification provides a considerable improvement to the match to the reference (benchmark) results, corresponding to the recorded ground motion model. As the degree of inelastic behavior increases, that is for larger value or $R$ or for ESD system (compared to EPH system), the differences to the reference results increases. Also, for large degrees of modification, larger errors may exist for such instances of significant inelastic behavior. The moderate modification approach (i.e., $C_{l}$ or $U_{t}$ Pareto points) proposed in (Tsioulou et al. 2018a; Tsioulou et al. 2018b) appears to consistently yield good results across all seismicity scenarios and types of inelastic behavior. Trends were similar for both considered EDPs. With respect to the two types of modifications examined, IM compatibility (IMC) and hazard compatibility (HC), while both match the median statistics similarly well, HC was shown to provide an enhanced match to the target dispersion, with IMC constrained to small dispersion values.

This study focused on SDoF systems' response and higher mode effects were thus not considered. Though the commented general trends (for example how the degree of inelastic behavior impacts the comparisons) are generalizable, future studies focusing on multiple-degree-of-freedom systems and additional EDPs are an important extension of this work. It is also worth noting that the intent of this study was not to provide a definite judgment about the specific stochastic ground motion simulation method, but rather to illustrate and validate the proposed modification and discuss possible outcomes. The identified similarities to recorded ground motions should provide confidence in using the modification method for engineering applications, while the discrepancies observed for some seismicity scenarios for highly inelastic response cases, emphasizes domains of potential improvement for future stochastic ground motion simulation methods or their potential modification.

\section{Appendix A: Details for the stochastic ground motion modification framework}

The statistical characterization $p_{g}\left(\ln \left(S_{a}\left(T_{i}\right)\right) \mid \boldsymbol{\mu}, \boldsymbol{\Sigma}\right)$ for $\operatorname{IM} S_{a}\left(T_{i}\right)$ through the stochastic ground motion model can be obtained by propagating the uncertainty originating from the predictive relationship $p(\boldsymbol{\theta} \mid \boldsymbol{\mu}, \boldsymbol{\Sigma})$ for the model parameter vector $\boldsymbol{\theta}$ and the stochastic sequence involved in the model description, denoted $\mathbf{w}$ herein. Following (Tsioulou et al. 2018b) the statistical characterization for the $\log \mathrm{IM}, \ln \left(S_{a}\left(T_{i}\right)\right)$, is approximated as Gaussian with mean and variance:

$$
\ln \left(\bar{S}_{a}^{g}\left(T_{i}, \boldsymbol{\mu}, \boldsymbol{\Sigma}\right)\right)=\iint \ln \left(S_{a}^{g}\left(T_{i}, \boldsymbol{\theta}, \mathbf{w}\right)\right) p(\boldsymbol{\theta} \mid \boldsymbol{\mu}, \boldsymbol{\Sigma}) p(\mathbf{w}) d \boldsymbol{\theta} d \mathbf{w}
$$




$$
\left(\sigma^{g}\left(T_{i}, \boldsymbol{\mu}, \boldsymbol{\Sigma}\right)\right)^{2}==\iint\left[\ln \left(S_{a}\left(T_{i}, \boldsymbol{\theta}, \mathbf{w}\right)\right)-\ln \left(\bar{S}_{a}^{g}\left(T_{i}, \boldsymbol{\mu}, \boldsymbol{\Sigma}\right)\right)\right]^{2} p(\boldsymbol{\theta} \mid \boldsymbol{\mu}, \boldsymbol{\Sigma}) p(\mathbf{w}) d \boldsymbol{\theta} d \mathbf{w}
$$

where $p(\mathbf{w})$ is the probability distribution for the stochastic sequence $\mathbf{w}$ and $S_{a}^{g}\left(T_{i}, \boldsymbol{\theta}, \mathbf{w}\right)$ denotes the estimate for $S_{a}\left(T_{i}\right)$ established through the stochastic ground motion model for specific values of the model parameter vector $\boldsymbol{\theta}$ and a specific white noise sequence $\mathbf{w}$ [i.e. for a specific ground motion time-history provided through the model]. Equations (A.1) and (A.2) ultimately represent the uncertainty propagation (from $\boldsymbol{\theta}$ and $\mathbf{w}$ ) to estimate the probability distribution for $S_{a}\left(T_{i}\right)$, in this case approximated as a lognormal distribution.

The hazard compatible modification of the probability model for $\boldsymbol{\theta}$, ultimately of the parametric description defined through $\boldsymbol{\mu}$ and $\boldsymbol{\Sigma}$, is formulated as a multi-objective optimization problem

$$
[\boldsymbol{\mu}, \boldsymbol{\Sigma}]^{*}=\arg \min \left\{F_{1}(\boldsymbol{\mu}, \boldsymbol{\Sigma} \mid \mathbf{z}), F_{2}(\boldsymbol{\mu}, \boldsymbol{\Sigma} \mid \mathbf{z})\right\}
$$

As discussed in Section 2, the first objective $F_{1}$ is the discrepancy between the target and predicted hazard probabilistic descriptions, quantified through the relative entropy as (Tsioulou et al. 2018b)

$$
F_{1}(\boldsymbol{\mu}, \boldsymbol{\Sigma} \mid \mathbf{z})=\frac{1}{\sum_{i=1}^{n_{y}} \gamma_{i}} \sum_{i=1}^{n_{y}} \gamma_{i} \int_{\mathbb{R}} p_{g}\left(\ln \left(S_{a}\left(T_{i}\right)\right) \mid \boldsymbol{\mu}, \boldsymbol{\Sigma}\right) \log \left[\frac{p_{g}\left(\ln \left(S_{a}\left(T_{i}\right)\right) \mid \boldsymbol{\mu}, \boldsymbol{\Sigma}\right)}{p_{t}\left(\ln \left(S_{a}\left(T_{1}\right)\right) \mid \mathbf{z}\right)}\right] d \ln \left(S_{a}\left(T_{i}\right)\right) \text { (A.4) }
$$

where the integral corresponds to the relative entropy of the compared distributions and $\gamma_{i}$ represent the weights prioritizing the match to different IM components (spectral accelerations at different structural periods), taken in this study all equal to 1 . For the typical case, which is the one examined in this paper, that $p_{t}\left(\ln \left(S_{a}\left(T_{i}\right)\right) \mid \mathbf{z}\right)$ corresponds also to a Gaussian description for $\ln \left(S_{a}\left(T_{i}\right)\right)$ with mean $\ln \left(\bar{S}_{a}\left(T_{i}, \mathbf{z}\right)\right)$ and variance $\sigma^{2}\left(T_{i}, \mathbf{z}\right), F_{1}$ in (A.4) has closed-form solution

$$
\begin{aligned}
& F_{1}(\boldsymbol{\mu}, \mathbf{\Sigma} \mid \mathbf{z})=\frac{1}{\sum_{i=1}^{n_{y}} \gamma_{i}} \sum_{i=1}^{n_{y}} \gamma_{i} \cdot \\
& \left\{\frac{\left(\ln \left(\bar{S}_{a}^{g}\left(T_{i}, \boldsymbol{\mu}, \mathbf{\Sigma}\right)\right)-\ln \left(\bar{S}_{a}\left(T_{i}, \mathbf{z}\right)\right)\right)^{2}}{2 \sigma^{2}\left(T_{i}, \mathbf{z}\right)}+\frac{1}{2}\left[\frac{\left(\sigma^{g}\left(T_{i}, \boldsymbol{\mu}, \mathbf{\Sigma}\right)\right)^{2}}{\sigma^{2}\left(T_{i}, \mathbf{z}\right)}-1-\ln \left(\frac{\left(\sigma^{g}\left(T_{i}, \boldsymbol{\mu}, \mathbf{\Sigma}\right)\right)^{2}}{\sigma^{2}\left(T_{i}, \mathbf{z}\right)}\right)\right]\right\}
\end{aligned}
$$

Objective $F_{2}$ is quantified by the entropy between the original probability model $p\left(\boldsymbol{\theta} \mid \boldsymbol{\mu}_{r}(\mathbf{z}), \boldsymbol{\Sigma}_{r}\right)$, and the modified one, $p(\boldsymbol{\theta} \mid \boldsymbol{\mu}, \boldsymbol{\Sigma})$

$$
\begin{aligned}
F_{2}(\boldsymbol{\mu}, \boldsymbol{\Sigma} \mid \mathbf{z}) & =\int_{\mathfrak{R}^{n_{\theta}}} p(\boldsymbol{\theta} \mid \boldsymbol{\mu}, \boldsymbol{\Sigma}) \log \left[\frac{p(\boldsymbol{\theta} \mid \boldsymbol{\mu}, \boldsymbol{\Sigma})}{p\left(\boldsymbol{\theta} \mid \boldsymbol{\mu}_{r}(\mathbf{z}), \boldsymbol{\Sigma}_{r}\right)}\right] d \boldsymbol{\theta} \\
& =\frac{1}{2}\left[\operatorname{tr}\left[\mathbf{\Sigma} \boldsymbol{\Sigma}_{r}^{-1}\right]+\left(\boldsymbol{\mu}_{r}(\mathbf{z})-\boldsymbol{\mu}\right)^{T} \boldsymbol{\Sigma}_{r}^{-1}\left(\boldsymbol{\mu}_{r}(\mathbf{z})-\boldsymbol{\mu}\right)-n_{\theta}-\ln \left(\operatorname{det}\left[\mathbf{\Sigma} \boldsymbol{\Sigma}_{r}^{-1}\right]\right)\right]
\end{aligned}
$$

where $\operatorname{tr}[$.$] and \operatorname{det}[$.$] stand for trace and determinant, respectively, and n_{\theta}$ corresponds to the dimension of the $\boldsymbol{\theta}$ vector.

The Pareto set corresponding to the multi-objective optimization problem of Equation (A.3) can be identified through any standard numerical approach, for example through genetic algorithms or stochastic search, provided that the two objectives $F_{1}$ and $F_{2}$ can be efficiently estimated. For objective $F_{1}$ this represents a challenge, since its estimation involves the high-dimensional integrals described by Equations (A.1) and (A.2). A framework relying on surrogate modelling was established in (Tsioulou et al. 2018b) to facilitate a 
computational efficient implementation. Foundation of the framework is the development of a surrogate model approximation for the conditional on $\boldsymbol{\theta}$ statistics, with total statistics [corresponding ultimately to Equations (A.1) and (A.2)] calculated through Monte Carlo integration leveraging the computational efficiency of the aforementioned surrogate model. Though computational burden for development of the surrogate model is considerable, this is a one-time cost; once the surrogate model is developed it can be implemented to support an efficient identification of the Pareto front of Equation (A.3) for any desired scenario $\mathbf{z}$.

Beyond the ground motion modification framework that established hazard-compatibility, a simplified implementation also exists (Tsioulou et al. 2018a) that focuses only on compatibility for the mean IM, completely ignoring variability in the predictive relationships and ultimately representing $p(\boldsymbol{\theta} \mid \boldsymbol{\mu}, \boldsymbol{\Sigma})$ simply by $\boldsymbol{\mu}$ (i.e., assumes $\boldsymbol{\Sigma}=0$ ). This means that the median IM prediction in Equation (A.1) simplifies to

$$
\bar{S}_{a}^{g}\left(T_{i}, \boldsymbol{\mu}\right)=\int S_{a}^{g}\left(T_{i}, \boldsymbol{\mu}, \mathbf{w}\right) p(\mathbf{w}) d \mathbf{w}
$$

since only source of variability is $\mathbf{w}$, while the variance $\sigma^{g}\left(T_{i}, \boldsymbol{\mu}\right)$ cannot be directly controlled (only contributing factor is $\mathbf{w}$ ) and therefore is ignored. The ground motion modification in this case focuses simply on matching the median IM and corresponds to adjustment of objectives $F_{1}$ and $F_{2}$, respectively, to

$$
\begin{aligned}
& F_{1}=\frac{1}{\sum_{i=1}^{n_{y}} \gamma_{i}} \sum_{i=1}^{n_{y}} \gamma_{i} \frac{1}{2}\left(\frac{\bar{S}_{a}^{g}\left(T_{i}, \boldsymbol{\mu}\right)-\bar{S}_{a}\left(T_{i}, \mathbf{z}\right)}{\bar{S}_{a}\left(T_{i}, \mathbf{z}\right)}\right)^{2} \\
& F_{2}=\frac{1}{2}\left(\boldsymbol{\mu}_{r}(\mathbf{z})-\boldsymbol{\mu}\right)^{T} \boldsymbol{\Sigma}_{r}^{-1}\left(\boldsymbol{\mu}_{r}(\mathbf{z})-\boldsymbol{\mu}\right)
\end{aligned}
$$

The identification of the Pareto front in this case is based on a similar surrogate modeling approximation and it is implemented with even higher computational efficiency (Tsioulou et al. 2018a), since estimation of $F_{1}$

\begin{tabular}{|c|c|c|c|c|c|c|c|c|}
\hline \multicolumn{8}{|c|}{ Scenario 1} & \multirow[b]{2}{*}{ Componen } \\
\hline Waveform ID & Earthquake ID & $\begin{array}{c}\text { Station } \\
\text { ID }\end{array}$ & $\begin{array}{c}\text { Earthquake } \\
\text { Name }\end{array}$ & Date & $\mathbf{M}$ & $\begin{array}{l}\text { Fault } \\
\text { Type }\end{array}$ & $\begin{array}{c}\text { Epicentral } \\
\text { Distance }[\mathbf{k m}]\end{array}$ & \\
\hline 408 & 159 & ATHA & $\begin{array}{c}\text { Athens_mainsho } \\
\text { ck }\end{array}$ & 7/9/1999 & 6 & & 18.66 & $\mathrm{y}$ \\
\hline 318 & 133 & CRP & $\begin{array}{c}\text { EMILIA_Pianur } \\
\text { a_Padana }\end{array}$ & $29 / 5 / 2012$ & 6 & reverse & 18.69 & $\mathrm{y}$ \\
\hline 448 & 92 & NOR & $\begin{array}{c}\text { Whittier } \\
\text { Narrows } \\
\end{array}$ & $1 / 10 / 1987$ & 6 & reverse & 14.93 & $\mathrm{x}$ \\
\hline 345 & 142 & TPLC & Christchurch & $21 / 2 / 2011$ & 6.2 & reverse & 19.97 & $\mathrm{y}$ \\
\hline 212 & 81 & $\begin{array}{c}\text { AI_013_- } \\
\text { CER }\end{array}$ & Duzce 2 & $6 / 6 / 2000$ & 6 & normal & 15.23 & $\mathrm{x}$ \\
\hline 428 & 75 & BUI & Friuli 4th shock & $15 / 9 / 1976$ & 5.9 & reverse & 11.26 & $\mathrm{x}$ \\
\hline 408 & 159 & ATHA & $\begin{array}{c}\text { Athens_mainsho } \\
\text { ck }\end{array}$ & 7/9/1999 & 6 & & 18.66 & $\mathrm{x}$ \\
\hline 320 & 133 & SAG0 & $\begin{array}{c}\text { EMILIA_Pianur } \\
\text { a_Padana }\end{array}$ & $29 / 5 / 2012$ & 6 & reverse & 24.98 & $\mathrm{y}$ \\
\hline 7 & 4 & TKY010 & $\begin{array}{c}\text { Near } \\
\text { Miyakejima } \\
\text { Island } \\
\end{array}$ & $8 / 7 / 2000$ & 5.9 & normal & 17.53 & $\mathrm{y}$ \\
\hline 286 & 125 & YMN006 & $\begin{array}{l}\text { MT FUJI } \\
\text { REGION } \\
\end{array}$ & $15 / 3 / 2011$ & 5.9 & strike-slip & 19.78 & $\mathrm{y}$ \\
\hline 74 & 25 & KGS001 & $\begin{array}{c}\text { NW Kagoshima } \\
\text { Prefecture }\end{array}$ & $26 / 3 / 1997$ & 6.1 & strike-slip & 29.53 & $\mathrm{y}$ \\
\hline
\end{tabular}
involves no Monte Carlo integration step (no uncertainty to address with respect to $\boldsymbol{\theta}$ ).

\section{Appendix B: Details for the ground motion records selected in REXEL}




\begin{tabular}{|c|c|c|c|c|c|c|c|c|}
\hline 383 & 149 & CACS & Christchurch & 13/6/2011 & 6 & reverse & 19.34 & $\mathrm{x}$ \\
\hline 254 & 114 & FKS015 & $\begin{array}{c}\text { EASTERN } \\
\text { FUKUSHIMA } \\
\text { PREF }\end{array}$ & $12 / 4 / 2011$ & 5.9 & strike-slip & 23.85 & y \\
\hline 271 & 122 & NGN001 & $\begin{array}{l}\text { MID NIIGATA } \\
\text { PREF }\end{array}$ & $11 / 3 / 2011$ & 6.2 & reverse & 25.38 & $\mathrm{y}$ \\
\hline 318 & 133 & CRP & $\begin{array}{c}\text { EMILIA_Pianur } \\
\text { a_Padana }\end{array}$ & $29 / 5 / 2012$ & 6 & reverse & 18.69 & $\mathrm{x}$ \\
\hline 282 & 125 & SZO008 & $\begin{array}{l}\text { MT FUJI } \\
\text { REGION }\end{array}$ & $15 / 3 / 2011$ & 5.9 & strike-slip & 27.77 & $\mathrm{x}$ \\
\hline 385 & 149 & KPOC & Christchurch & $13 / 6 / 2011$ & 6 & reverse & 21.61 & $\mathrm{y}$ \\
\hline 322 & 133 & CASO & $\begin{array}{c}\text { EMILIA_Pianur } \\
\text { a_Padana }\end{array}$ & $29 / 5 / 2012$ & 6 & reverse & 26.25 & $\mathrm{x}$ \\
\hline 38 & 15 & MYG013 & $\begin{array}{l}\text { N Miyagi } \\
\text { Prefecture }\end{array}$ & $25 / 7 / 2003$ & 6.1 & reverse & 26.1 & $\mathrm{x}$ \\
\hline 38 & 15 & MYG013 & $\begin{array}{l}\text { N Miyagi } \\
\text { Prefecture }\end{array}$ & $25 / 7 / 2003$ & 6.1 & reverse & 26.1 & $\mathrm{y}$ \\
\hline 430 & 75 & TRC & Friuli 4th shock & $15 / 9 / 1976$ & 5.9 & reverse & 10.04 & $\mathrm{x}$ \\
\hline 271 & 122 & NGN001 & $\begin{array}{l}\text { MID NIIGATA } \\
\text { PREF }\end{array}$ & $11 / 3 / 2011$ & 6.2 & reverse & 25.38 & $\bar{x}$ \\
\hline 93 & 28 & SMN013 & $\begin{array}{l}\text { Yamaguchi } \\
\text { Prefecture }\end{array}$ & $25 / 6 / 1997$ & 5.8 & strike-slip & 29.01 & $\mathrm{x}$ \\
\hline 261 & 118 & SZO005 & $\begin{array}{c}\text { SOUTHERN } \\
\text { SURUGA BAY } \\
\text { REG }\end{array}$ & $1 / 8 / 2011$ & 5.8 & reverse & 18.08 & $\mathrm{x}$ \\
\hline 212 & 81 & $\begin{array}{c}\text { AI_013_ } \\
\text { CER }\end{array}$ & Duzce 2 & $6 / 6 / 2000$ & 6 & normal & 15.23 & y \\
\hline 342 & 142 & ROLC & Christchurch & $21 / 2 / 2011$ & 6.2 & reverse & 26.57 & $\mathrm{x}$ \\
\hline 342 & 142 & ROLC & Christchurch & $21 / 2 / 2011$ & 6.2 & reverse & 26.57 & $\mathrm{y}$ \\
\hline 253 & 114 & FKS014 & $\begin{array}{c}\text { EASTERN } \\
\text { FUKUSHIMA } \\
\text { PREF }\end{array}$ & $12 / 4 / 2011$ & 5.9 & strike-slip & 27.93 & $\mathrm{x}$ \\
\hline 428 & 75 & BUI & Friuli 4th shock & $15 / 9 / 1976$ & 5.9 & reverse & 11.26 & $\mathrm{y}$ \\
\hline 156 & 53 & FKS028 & $\begin{array}{l}\text { Mid Niigata } \\
\text { Prefecture }\end{array}$ & $\begin{array}{c}27 / 10 / 200 \\
4\end{array}$ & 5.8 & reverse & 26.07 & $\mathrm{y}$ \\
\hline
\end{tabular}

\begin{tabular}{|c|c|c|c|c|c|c|c|c|}
\hline \multicolumn{8}{|c|}{ Scenario 2} & \multirow[b]{2}{*}{ Component } \\
\hline Waveform ID & Earthquake ID & $\begin{array}{l}\text { Station } \\
\text { ID }\end{array}$ & $\begin{array}{l}\text { Earthquake } \\
\text { Name }\end{array}$ & Date & $\mathbf{M}$ & $\begin{array}{l}\text { Fault } \\
\text { Type }\end{array}$ & $\begin{array}{c}\text { Epicentral } \\
\text { Distance }[\mathrm{km}]\end{array}$ & \\
\hline 332 & 137 & RKAC & Darfield & $3 / 9 / 2010$ & 7.1 & strike-slip & 25.87 & $\mathrm{y}$ \\
\hline 335 & 137 & TPLC & Darfield & $3 / 9 / 2010$ & 7.1 & strike-slip & 23.58 & $\mathrm{x}$ \\
\hline 141 & 51 & IWT011 & $\begin{array}{c}\text { Southern Iwate } \\
\text { Prefecture }\end{array}$ & $13 / 6 / 2008$ & 6.9 & reverse & 26.89 & $\mathrm{x}$ \\
\hline 140 & 51 & AKT023 & $\begin{array}{c}\text { Southern Iwate } \\
\text { Prefecture }\end{array}$ & $13 / 6 / 2008$ & 6.9 & reverse & 18.82 & $\mathrm{x}$ \\
\hline 332 & 137 & RKAC & Darfield & $3 / 9 / 2010$ & 7.1 & strike-slip & 25.87 & $\mathrm{x}$ \\
\hline 413 & 46 & ALT & Irpinia & $\begin{array}{c}23 / 11 / 198 \\
0 \\
\end{array}$ & 6.9 & normal & 23.77 & $\mathrm{y}$ \\
\hline 140 & 51 & AKT023 & $\begin{array}{c}\text { Southern Iwate } \\
\text { Prefecture }\end{array}$ & $13 / 6 / 2008$ & 6.9 & reverse & 18.82 & $\mathrm{y}$ \\
\hline 138 & 50 & ISK003 & $\begin{array}{l}\text { Off Noto } \\
\text { Peninsula }\end{array}$ & $25 / 3 / 2007$ & 6.7 & reverse & 27.17 & $\mathrm{x}$ \\
\hline 458 & 99 & $\begin{array}{c}\text { ST_2408 } \\
7\end{array}$ & Northridge & $17 / 1 / 1994$ & 6.7 & reverse & 11.02 & $\mathrm{y}$ \\
\hline 463 & 99 & $\begin{array}{c}\text { ST_2468 } \\
8 \\
\end{array}$ & Northridge & 17/1/1994 & 6.7 & reverse & 18.59 & $\mathrm{x}$ \\
\hline 441 & 87 & DAY & Tabas & $16 / 9 / 1978$ & 7.1 & reverse & 20.63 & $\mathrm{y}$ \\
\hline 139 & 51 & IWT010 & $\begin{array}{c}\text { Southern Iwate } \\
\text { Prefecture }\end{array}$ & $13 / 6 / 2008$ & 6.9 & reverse & 23.08 & $\mathrm{x}$ \\
\hline 460 & 99 & $\begin{array}{c}\text { ST_2430 } \\
3\end{array}$ & Northridge & $17 / 1 / 1994$ & 6.7 & reverse & 23.62 & $\mathrm{y}$ \\
\hline 454 & 94 & $\begin{array}{c}\text { ST_4700 } \\
6 \\
\end{array}$ & Loma Prieta & $\begin{array}{c}\text { 18/10/198 } \\
9 \\
\end{array}$ & 6.9 & oblique & 28.83 & $\mathrm{x}$ \\
\hline 440 & 86 & KAR & Gazli & $17 / 5 / 1976$ & 6.7 & reverse & 12.78 & $\mathrm{y}$ \\
\hline 328 & 137 & CACS & Darfield & $3 / 9 / 2010$ & 7.1 & strike-slip & 29.19 & $\mathrm{y}$ \\
\hline 304 & 94 & LGPC & Loma Prieta & $\begin{array}{c}18 / 10 / 198 \\
9 \\
\end{array}$ & 6.9 & oblique & 18.75 & $\mathrm{x}$ \\
\hline
\end{tabular}




\begin{tabular}{|c|c|c|c|c|c|c|c|c|}
\hline 441 & 87 & DAY & Tabas & 16/9/1978 & 7.1 & reverse & 20.63 & $\mathrm{x}$ \\
\hline 440 & 86 & KAR & Gazli & $17 / 5 / 1976$ & 6.7 & reverse & 12.78 & $\mathrm{x}$ \\
\hline 456 & 94 & $\begin{array}{c}\text { ST_5806 } \\
5\end{array}$ & Loma Prieta & $\begin{array}{c}18 / 10 / 198 \\
9\end{array}$ & 6.9 & oblique & 27.59 & $\mathrm{y}$ \\
\hline 335 & 137 & TPLC & Darfield & $3 / 9 / 2010$ & 7.1 & strike-slip & 23.58 & $\mathrm{y}$ \\
\hline 456 & 94 & $\begin{array}{c}\text { ST_5806 } \\
5\end{array}$ & Loma Prieta & $\begin{array}{c}18 / 10 / 198 \\
9\end{array}$ & 6.9 & oblique & 27.59 & $\mathrm{x}$ \\
\hline 139 & 51 & IWT010 & $\begin{array}{c}\text { Southern Iwate } \\
\text { Prefecture }\end{array}$ & $13 / 6 / 2008$ & 6.9 & reverse & 23.08 & $\mathrm{y}$ \\
\hline 413 & 46 & ALT & Irpinia & $\begin{array}{c}23 / 11 / 198 \\
0 \\
\end{array}$ & 6.9 & normal & 23.77 & $\mathrm{x}$ \\
\hline 460 & 99 & $\begin{array}{c}\text { ST_2430 } \\
3\end{array}$ & Northridge & $17 / 1 / 1994$ & 6.7 & reverse & 23.62 & $\mathrm{x}$ \\
\hline 459 & 99 & $\begin{array}{c}\text { ST_2438 } \\
9\end{array}$ & Northridge & $17 / 1 / 1994$ & 6.7 & reverse & 20.19 & $\mathrm{x}$ \\
\hline 455 & 94 & $\begin{array}{c}\text { ST_5813 } \\
5 \\
\end{array}$ & Loma Prieta & $\begin{array}{c}18 / 10 / 198 \\
9 \\
\end{array}$ & 6.9 & oblique & 16.41 & $\mathrm{y}$ \\
\hline 328 & 137 & CACS & Darfield & $3 / 9 / 2010$ & 7.1 & strike-slip & 29.19 & $\mathrm{x}$ \\
\hline 334 & 137 & SBRC & Darfield & $3 / 9 / 2010$ & 7.1 & strike-slip & 29.5 & $\mathrm{x}$ \\
\hline 458 & 99 & $\begin{array}{c}\text { ST_2408 } \\
7\end{array}$ & Northridge & $17 / 1 / 1994$ & 6.7 & reverse & 11.02 & $\mathrm{x}$ \\
\hline
\end{tabular}

\begin{tabular}{|c|c|c|c|c|c|c|c|c|}
\hline \multicolumn{8}{|c|}{ Scenario 3} & \multirow[b]{2}{*}{ Componen } \\
\hline Waveform ID & Earthquake ID & $\begin{array}{l}\text { Station } \\
\text { ID }\end{array}$ & $\begin{array}{l}\text { Earthquake } \\
\text { Name }\end{array}$ & Date & $\mathbf{M}$ & $\begin{array}{l}\text { Fault } \\
\text { Type }\end{array}$ & $\begin{array}{c}\text { Epicentral } \\
\text { Distance }[\mathrm{km}]\end{array}$ & \\
\hline 335 & 137 & TPLC & Darfield & $3 / 9 / 2010$ & 7.1 & strike-slip & 23.58 & $\mathrm{y}$ \\
\hline 335 & 137 & TPLC & Darfield & $3 / 9 / 2010$ & 7.1 & strike-slip & 23.58 & $\mathrm{x}$ \\
\hline 412 & 35 & HEC & Hector Mine & $\begin{array}{c}6 / 10 / 199 \\
9\end{array}$ & 7.1 & strike-slip & 28.61 & $\mathrm{y}$ \\
\hline 328 & 137 & CACS & Darfield & $3 / 9 / 2010$ & 7.1 & strike-slip & 29.19 & $\mathrm{y}$ \\
\hline 328 & 137 & CACS & Darfield & $3 / 9 / 2010$ & 7.1 & strike-slip & 29.19 & $\mathrm{x}$ \\
\hline 310 & 39 & $\begin{array}{l}\text { AI_157_ } \\
\text { WF }\end{array}$ & Duzce & $\begin{array}{c}12 / 11 / 199 \\
9\end{array}$ & 7.1 & strike-slip & 30.22 & $\mathrm{x}$ \\
\hline 334 & 137 & SBRC & Darfield & $3 / 9 / 2010$ & 7.1 & strike-slip & 29.5 & $\mathrm{x}$ \\
\hline 334 & 137 & SBRC & Darfield & $3 / 9 / 2010$ & 7.1 & strike-slip & 29.5 & $\mathrm{y}$ \\
\hline 330 & 137 & DSLC & Darfield & $3 / 9 / 2010$ & 7.1 & strike-slip & 13.31 & $\mathrm{x}$ \\
\hline 332 & 137 & RKAC & Darfield & $3 / 9 / 2010$ & 7.1 & strike-slip & 25.87 & $\mathrm{x}$ \\
\hline 310 & 39 & $\begin{array}{c}\text { AI_157_ } \\
\text { WF }\end{array}$ & Duzce & $\begin{array}{c}12 / 11 / 199 \\
9 \\
\end{array}$ & 7.1 & strike-slip & 30.22 & $\mathrm{y}$ \\
\hline 332 & 137 & RKAC & Darfield & $3 / 9 / 2010$ & 7.1 & strike-slip & 25.87 & $\mathrm{y}$ \\
\hline 309 & 39 & $\begin{array}{c}\text { AI_158_ } \\
\text { LS }\end{array}$ & Duzce & $\begin{array}{c}12 / 11 / 199 \\
9\end{array}$ & 7.1 & strike-slip & 34.66 & $\mathrm{x}$ \\
\hline 441 & 87 & DAY & Tabas & $16 / 9 / 1978$ & 7.1 & reverse & 20.63 & $\mathrm{y}$ \\
\hline 207 & 39 & $\begin{array}{c}\text { AI_155_ } \\
\text { FP }\end{array}$ & Duzce & $\begin{array}{c}12 / 11 / 199 \\
9 \\
\end{array}$ & 7.1 & strike-slip & 27.44 & $\mathrm{y}$ \\
\hline 309 & 39 & $\begin{array}{c}\text { AI_158_ } \\
\text { LS }\end{array}$ & Duzce & $\begin{array}{c}12 / 11 / 199 \\
9\end{array}$ & 7.1 & strike-slip & 34.66 & $\mathrm{y}$ \\
\hline 207 & 39 & $\begin{array}{c}\text { AI_155_ } \\
\text { FP }\end{array}$ & Duzce & $\begin{array}{c}12 / 11 / 199 \\
9 \\
\end{array}$ & 7.1 & strike-slip & 27.44 & $\mathrm{x}$ \\
\hline 457 & 98 & $\begin{array}{c}\text { ST_2217 } \\
0 \\
\end{array}$ & Landers & $28 / 6 / 1992$ & 7.3 & strike-slip & 13.08 & $\mathrm{y}$ \\
\hline 441 & 87 & DAY & Tabas & $16 / 9 / 1978$ & 7.1 & reverse & 20.63 & $x$ \\
\hline 308 & 39 & $\begin{array}{c}\text { AI_159_- } \\
\text { FI }\end{array}$ & Duzce & $\begin{array}{c}12 / 11 / 199 \\
9 \\
\end{array}$ & 7.1 & strike-slip & 32.26 & $\mathrm{y}$ \\
\hline 333 & 137 & ROLC & Darfield & $3 / 9 / 2010$ & 7.1 & strike-slip & 16.97 & $\mathrm{y}$ \\
\hline 308 & 39 & $\begin{array}{c}\text { AI_159_ } \\
\text { FI }\end{array}$ & Duzce & $\begin{array}{c}12 / 11 / 199 \\
9 \\
\end{array}$ & 7.1 & strike-slip & 32.26 & $\mathrm{x}$ \\
\hline 330 & 137 & DSLC & Darfield & $3 / 9 / 2010$ & 7.1 & strike-slip & 13.31 & $\mathrm{y}$ \\
\hline 333 & 137 & ROLC & Darfield & $3 / 9 / 2010$ & 7.1 & strike-slip & 16.97 & $\mathrm{x}$ \\
\hline 206 & 39 & $\begin{array}{c}\text { AI_154_ } \\
\text { BV }\end{array}$ & Duzce & $\begin{array}{c}12 / 11 / 199 \\
9\end{array}$ & 7.1 & strike-slip & 15.6 & $\mathrm{x}$ \\
\hline 457 & 98 & $\begin{array}{c}\text { ST_2217 } \\
0\end{array}$ & Landers & $28 / 6 / 1992$ & 7.3 & strike-slip & 13.08 & $\mathrm{x}$ \\
\hline
\end{tabular}




\begin{tabular}{|c|c|c|c|c|c|c|c|c|}
\hline 206 & 39 & AI_154_ & Duzce & $\begin{array}{c}12 / 11 / 199 \\
9\end{array}$ & 7.1 & strike-slip & 15.6 & y \\
\hline 208 & 39 & AI_156_ & Duzce & $\begin{array}{c}12 / 11 / 199 \\
9\end{array}$ & 7.1 & strike-slip & 27.16 & x \\
\hline 412 & 35 & HEC & Hector Mine & $\begin{array}{c}16 / 10 / 199 \\
9\end{array}$ & 7.1 & strike-slip & 28.61 & x \\
\hline 331 & 137 & HORC & Darfield & $3 / 9 / 2010$ & 7.1 & strike-slip & 17.82 & y \\
\hline
\end{tabular}

\begin{tabular}{|c|c|c|c|c|c|c|c|c|}
\hline \multicolumn{8}{|c|}{ Scenario 4} & \multirow[b]{2}{*}{ Component } \\
\hline Waveform ID & Earthquake ID & $\begin{array}{l}\text { Station } \\
\text { ID }\end{array}$ & $\begin{array}{l}\text { Earthquake } \\
\text { Name }\end{array}$ & Date & $\mathbf{M}$ & $\begin{array}{l}\text { Fault } \\
\text { Type }\end{array}$ & $\begin{array}{c}\text { Epicentral } \\
\text { Distance }[\mathbf{k m}]\end{array}$ & \\
\hline 5674 & 1839 & ST2963 & Kopaonik & $18 / 5 / 1980$ & 5.9 & oblique & 84 & $\mathrm{y}$ \\
\hline 1738 & 170 & ST604 & Biga & $5 / 7 / 1983$ & 6.1 & oblique & 77 & $\mathrm{x}$ \\
\hline 6971 & 473 & ST771 & $\begin{array}{c}\text { Izmit } \\
\text { (aftershock) }\end{array}$ & $13 / 9 / 1999$ & 5.8 & oblique & 61 & $\mathrm{y}$ \\
\hline 2030 & 169 & ST171 & $\begin{array}{c}\text { Kefallinia } \\
\text { (aftershock) }\end{array}$ & $23 / 3 / 1983$ & 6.2 & oblique & 65 & $\mathrm{y}$ \\
\hline 2030 & 169 & ST171 & $\begin{array}{c}\text { Kefallinia } \\
\text { (aftershock) }\end{array}$ & $23 / 3 / 1983$ & 6.2 & oblique & 65 & $\mathrm{x}$ \\
\hline 1781 & 581 & ST1263 & Cicektepe & $5 / 12 / 1995$ & 5.8 & strike slip & 65 & $\mathrm{y}$ \\
\hline 7160 & 2313 & ST3295 & Firuzabad & $20 / 6 / 1994$ & 5.9 & strike slip & 58 & $\mathrm{y}$ \\
\hline 351 & 170 & ST130 & Biga & $5 / 7 / 1983$ & 6.1 & oblique & 84 & $\mathrm{y}$ \\
\hline 1240 & 473 & ST561 & $\begin{array}{c}\text { Izmit } \\
\text { (aftershock) }\end{array}$ & $13 / 9 / 1999$ & 5.8 & oblique & 54 & $\mathrm{x}$ \\
\hline 547 & 259 & ST210 & Izmir & $6 / 11 / 1992$ & 6 & strike slip & 63 & $\mathrm{y}$ \\
\hline 364 & 175 & ST139 & Lazio Abruzzo & $7 / 5 / 1984$ & 5.9 & normal & 58 & $\mathrm{x}$ \\
\hline 367 & 175 & ST142 & Lazio Abruzzo & $7 / 5 / 1984$ & 5.9 & normal & 72 & $y$ \\
\hline 1979 & 260 & ST1352 & Tithorea & $\begin{array}{c}18 / 11 / 199 \\
2\end{array}$ & 5.9 & normal & 83 & $\mathrm{x}$ \\
\hline 143 & 65 & ST15 & $\begin{array}{c}\text { Friuli } \\
\text { (aftershock) }\end{array}$ & $15 / 9 / 1976$ & 6 & thrust & 80 & $\mathrm{x}$ \\
\hline 529 & 248 & ST199 & $\begin{array}{c}\text { Racha } \\
\text { (aftershock) }\end{array}$ & $15 / 6 / 1991$ & 6 & thrust & 72 & $\mathrm{x}$ \\
\hline 6962 & 473 & ST3271 & $\begin{array}{c}\text { Izmit } \\
\text { (aftershock) }\end{array}$ & 13/9/1999 & 5.8 & oblique & 50 & $\mathrm{y}$ \\
\hline 547 & 259 & ST210 & Izmir & $6 / 11 / 1992$ & 6 & strike slip & 63 & $\mathrm{x}$ \\
\hline 376 & 175 & ST150 & Lazio Abruzzo & $7 / 5 / 1984$ & 5.9 & normal & 69 & $y$ \\
\hline 1793 & 259 & ST571 & Izmir & $6 / 11 / 1992$ & 6 & strike slip & 58 & $\mathrm{y}$ \\
\hline 172 & 81 & ST48 & Basso Tirreno & $15 / 4 / 1978$ & 6 & oblique & 58 & $\mathrm{x}$ \\
\hline 616 & 286 & ST134 & Umbria Marche & $26 / 9 / 1997$ & 6 & normal & 59 & $y$ \\
\hline 1781 & 581 & ST1263 & Cicektepe & $5 / 12 / 1995$ & 5.8 & strike slip & 65 & $\mathrm{x}$ \\
\hline 1890 & 260 & ST1319 & Tithorea & $\begin{array}{c}18 / 11 / 199 \\
2\end{array}$ & 5.9 & normal & 61 & $\mathrm{x}$ \\
\hline 143 & 65 & ST15 & $\begin{array}{c}\text { Friuli } \\
\text { (aftershock) }\end{array}$ & $15 / 9 / 1976$ & 6 & thrust & 80 & $\mathrm{y}$ \\
\hline 367 & 175 & ST142 & Lazio Abruzzo & $7 / 5 / 1984$ & 5.9 & normal & 72 & $\mathrm{x}$ \\
\hline 364 & 175 & ST139 & Lazio Abruzzo & $7 / 5 / 1984$ & 5.9 & normal & 58 & $\mathrm{y}$ \\
\hline 1979 & 260 & ST1352 & Tithorea & $\begin{array}{c}18 / 11 / 199 \\
2\end{array}$ & 5.9 & normal & 83 & $\mathrm{y}$ \\
\hline 1795 & 191 & ST587 & Golbasi & $6 / 6 / 1986$ & 5.8 & strike slip & 52 & $\mathrm{y}$ \\
\hline 6971 & 473 & ST771 & $\begin{array}{c}\text { Izmit } \\
\text { (aftershock) }\end{array}$ & $13 / 9 / 1999$ & 5.8 & oblique & 61 & $\mathrm{x}$ \\
\hline 467 & 224 & ST181 & Chenoua & $\begin{array}{c}29 / 10 / 198 \\
9\end{array}$ & 5.9 & thrust & 50 & $\mathrm{x}$ \\
\hline
\end{tabular}

\begin{tabular}{|c|c|c|c|c|c|c|c|c|}
\hline \multicolumn{9}{|c|}{ Scenario 5 } \\
\hline Waveform ID & Earthquake ID & $\begin{array}{c}\text { Station } \\
\text { ID }\end{array}$ & $\begin{array}{c}\text { Earthquake } \\
\text { Name }\end{array}$ & Date & M & $\begin{array}{c}\text { Fault } \\
\text { Type }\end{array}$ & $\begin{array}{c}\text { Epicentral } \\
\text { Distance }[\mathbf{k m}]\end{array}$ & Component \\
\hline 256 & 122 & ST87 & Azores & $1 / 1 / 1980$ & 6.9 & strike slip & 80 & x \\
\hline 299 & 146 & ST105 & $\begin{array}{c}\text { Campano } \\
\text { Lucano }\end{array}$ & $\begin{array}{c}23 / 11 / 198 \\
0\end{array}$ & 6.9 & normal & 52 & $\mathrm{x}$ \\
\hline
\end{tabular}




\begin{tabular}{|c|c|c|c|c|c|c|c|c|}
\hline 202 & 93 & ST70 & Montenegro & $15 / 4 / 1979$ & 6.9 & thrust & 56 & $\mathrm{y}$ \\
\hline 299 & 146 & ST105 & $\begin{array}{c}\text { Campano } \\
\text { Lucano }\end{array}$ & $\begin{array}{c}23 / 11 / 198 \\
0\end{array}$ & 6.9 & normal & 52 & $\mathrm{y}$ \\
\hline 202 & 93 & ST70 & Montenegro & $15 / 4 / 1979$ & 6.9 & thrust & 56 & $\mathrm{x}$ \\
\hline 295 & 146 & ST101 & $\begin{array}{l}\text { Campano } \\
\text { Lucano }\end{array}$ & $\begin{array}{c}23 / 11 / 198 \\
0\end{array}$ & 6.9 & normal & 58 & $\mathrm{X}$ \\
\hline 286 & 146 & ST92 & $\begin{array}{c}\text { Campano } \\
\text { Lucano }\end{array}$ & $\begin{array}{c}23 / 11 / 198 \\
0 \\
\end{array}$ & 6.9 & normal & 78 & $\mathrm{y}$ \\
\hline 256 & 122 & ST87 & Azores & $1 / 1 / 1980$ & 6.9 & strike slip & 80 & $\mathrm{y}$ \\
\hline 297 & 146 & ST103 & $\begin{array}{c}\text { Campano } \\
\text { Lucano }\end{array}$ & $\begin{array}{c}23 / 11 / 198 \\
0\end{array}$ & 6.9 & normal & 72 & $\mathrm{y}$ \\
\hline 297 & 146 & ST103 & $\begin{array}{c}\text { Campano } \\
\text { Lucano }\end{array}$ & $\begin{array}{c}23 / 11 / 198 \\
0 \\
\end{array}$ & 6.9 & normal & 72 & $\mathrm{x}$ \\
\hline 195 & 93 & ST66 & Montenegro & $15 / 4 / 1979$ & 6.9 & thrust & 55 & $\mathrm{y}$ \\
\hline 286 & 146 & ST92 & $\begin{array}{c}\text { Campano } \\
\text { Lucano }\end{array}$ & $\begin{array}{c}23 / 11 / 198 \\
0\end{array}$ & 6.9 & normal & 78 & $\mathrm{x}$ \\
\hline 296 & 146 & ST102 & $\begin{array}{c}\text { Campano } \\
\text { Lucano }\end{array}$ & $\begin{array}{c}23 / 11 / 198 \\
0\end{array}$ & 6.9 & normal & 80 & $\mathrm{x}$ \\
\hline 153 & 67 & ST37 & Caldiran & $\begin{array}{c}24 / 11 / 197 \\
6\end{array}$ & 7 & strike slip & 52 & $\mathrm{y}$ \\
\hline 974 & 146 & ST307 & $\begin{array}{c}\text { Campano } \\
\text { Lucano }\end{array}$ & $\begin{array}{c}23 / 11 / 198 \\
0\end{array}$ & 6.9 & normal & 94 & $\mathrm{x}$ \\
\hline 195 & 93 & ST66 & Montenegro & $15 / 4 / 1979$ & 6.9 & thrust & 55 & $\mathrm{x}$ \\
\hline 295 & 146 & ST101 & $\begin{array}{c}\text { Campano } \\
\text { Lucano }\end{array}$ & $\begin{array}{c}23 / 11 / 198 \\
0\end{array}$ & 6.9 & normal & 58 & $\mathrm{y}$ \\
\hline 300 & 146 & ST106 & $\begin{array}{c}\text { Campano } \\
\text { Lucano }\end{array}$ & $\begin{array}{c}23 / 11 / 198 \\
0 \\
\end{array}$ & 6.9 & normal & 100 & $\mathrm{x}$ \\
\hline 300 & 146 & ST106 & $\begin{array}{c}\text { Campano } \\
\text { Lucano }\end{array}$ & $\begin{array}{c}23 / 11 / 198 \\
0\end{array}$ & 6.9 & normal & 100 & $\mathrm{y}$ \\
\hline 974 & 146 & ST307 & $\begin{array}{c}\text { Campano } \\
\text { Lucano }\end{array}$ & $\begin{array}{c}23 / 11 / 198 \\
0\end{array}$ & 6.9 & normal & 94 & $\mathrm{y}$ \\
\hline 304 & 146 & ST110 & $\begin{array}{c}\text { Campano } \\
\text { Lucano }\end{array}$ & $\begin{array}{c}23 / 11 / 198 \\
0 \\
\end{array}$ & 6.9 & normal & 64 & $\mathrm{x}$ \\
\hline 304 & 146 & ST110 & $\begin{array}{c}\text { Campano } \\
\text { Lucano }\end{array}$ & $\begin{array}{c}23 / 11 / 198 \\
0\end{array}$ & 6.9 & normal & 64 & $\mathrm{y}$ \\
\hline 302 & 146 & ST108 & $\begin{array}{c}\text { Campano } \\
\text { Lucano }\end{array}$ & $\begin{array}{c}23 / 11 / 198 \\
0\end{array}$ & 6.9 & normal & 92 & $\mathrm{y}$ \\
\hline 302 & 146 & ST108 & $\begin{array}{c}\text { Campano } \\
\text { Lucano }\end{array}$ & $\begin{array}{c}23 / 11 / 198 \\
0 \\
\end{array}$ & 6.9 & normal & 92 & $\mathrm{x}$ \\
\hline 153 & 67 & ST37 & Caldiran & $\begin{array}{c}24 / 11 / 197 \\
6\end{array}$ & 7 & strike slip & 52 & $\mathrm{x}$ \\
\hline 5794 & 1771 & ST2989 & Gulf of Akaba & $\begin{array}{c}22 / 11 / 199 \\
5\end{array}$ & 7.1 & oblique & 93 & $\mathrm{x}$ \\
\hline 5794 & 1771 & ST2989 & Gulf of Akaba & $\begin{array}{c}22 / 11 / 199 \\
5\end{array}$ & 7.1 & oblique & 93 & $\mathrm{y}$ \\
\hline 289 & 146 & ST95 & $\begin{array}{c}\text { Campano } \\
\text { Lucano }\end{array}$ & $\begin{array}{c}23 / 11 / 198 \\
0 \\
\end{array}$ & 6.9 & normal & 48 & $\mathrm{x}$ \\
\hline 288 & 146 & ST94 & $\begin{array}{c}\text { Campano } \\
\text { Lucano }\end{array}$ & $\begin{array}{c}23 / 11 / 198 \\
0\end{array}$ & 6.9 & normal & 43 & $\mathrm{y}$ \\
\hline 289 & 146 & ST95 & $\begin{array}{c}\text { Campano } \\
\text { Lucano }\end{array}$ & $\begin{array}{c}23 / 11 / 198 \\
0\end{array}$ & 6.9 & normal & 48 & $\mathrm{y}$ \\
\hline
\end{tabular}

\begin{tabular}{|c|c|c|c|c|c|c|c|c|}
\hline \multicolumn{7}{|c|}{ Scenario 6 } & Fault \\
\hline Waveform ID & Earthquake ID & $\begin{array}{c}\text { Station } \\
\text { ID }\end{array}$ & $\begin{array}{c}\text { Earthquake } \\
\text { Name }\end{array}$ & Date & M & $\begin{array}{c}\text { Epicentral } \\
\text { Distance [km] }\end{array}$ & Component \\
\hline 6761 & 2222 & ST40 & Vrancea & $30 / 8 / 1986$ & 7.2 & thrust & 49 & x \\
\hline 5794 & 1771 & ST2989 & Gulf of Akaba & $\begin{array}{c}22 / 11 / 199 \\
5\end{array}$ & 7.1 & oblique & 93 & y \\
\hline 479 & 230 & ST188 & Manjil & $20 / 6 / 1990$ & 7.4 & oblique & 81 & x \\
\hline 4343 & 472 & ST2574 & Izmit & $17 / 8 / 1999$ & 7.6 & strike slip & 96 & x \\
\hline 181 & 87 & ST53 & Tabas & $16 / 9 / 1978$ & 7.3 & oblique & 68 & y \\
\hline 181 & 87 & ST53 & Tabas & $16 / 9 / 1978$ & 7.3 & oblique & 68 & x \\
\hline 479 & 230 & ST188 & Manjil & $20 / 6 / 1990$ & 7.4 & oblique & 81 & y \\
\hline 1216 & 472 & ST544 & Izmit & $17 / 8 / 1999$ & 7.6 & strike slip & 93 & y \\
\hline 1251 & 472 & ST773 & Izmit & $17 / 8 / 1999$ & 7.6 & strike slip & 92 & x \\
\hline 1248 & 472 & ST774 & Izmit & $17 / 8 / 1999$ & 7.6 & strike slip & 55 & y \\
\hline
\end{tabular}




\begin{tabular}{|c|c|c|c|c|c|c|c|c|}
\hline 1216 & 472 & ST544 & Izmit & $17 / 8 / 1999$ & 7.6 & strike slip & 93 & $\mathrm{X}$ \\
\hline 153 & 67 & ST37 & Caldiran & $\begin{array}{c}24 / 11 / 197 \\
6\end{array}$ & 7 & strike slip & 52 & $\mathrm{X}$ \\
\hline 1255 & 472 & ST770 & Izmit & $17 / 8 / 1999$ & 7.6 & strike slip & 78 & $\mathrm{x}$ \\
\hline 6496 & 497 & ST3135 & Duzce 1 & $\begin{array}{c}12 / 11 / 199 \\
9\end{array}$ & 7.2 & oblique & 45 & $\mathrm{X}$ \\
\hline 6918 & 472 & ST775 & Izmit & $17 / 8 / 1999$ & 7.6 & strike slip & 95 & $\mathrm{y}$ \\
\hline 1218 & 472 & ST574 & Izmit & $17 / 8 / 1999$ & 7.6 & strike slip & 86 & $\mathrm{y}$ \\
\hline 476 & 230 & ST185 & Manjil & $20 / 6 / 1990$ & 7.4 & oblique & 97 & $\mathrm{y}$ \\
\hline 4340 & 472 & ST2572 & Izmit & $17 / 8 / 1999$ & 7.6 & strike slip & 93 & $\mathrm{y}$ \\
\hline 1229 & 472 & ST859 & Izmit & 17/8/1999 & 7.6 & strike slip & 73 & $\mathrm{y}$ \\
\hline 4343 & 472 & ST2574 & Izmit & $17 / 8 / 1999$ & 7.6 & strike slip & 96 & $\mathrm{y}$ \\
\hline 1218 & 472 & ST574 & Izmit & $17 / 8 / 1999$ & 7.6 & strike slip & 86 & $\mathrm{X}$ \\
\hline 1255 & 472 & ST770 & Izmit & $17 / 8 / 1999$ & 7.6 & strike slip & 78 & $\mathrm{y}$ \\
\hline 6499 & 497 & ST3140 & Duzce 1 & $\begin{array}{c}12 / 11 / 199 \\
9\end{array}$ & 7.2 & oblique & 42 & $\mathrm{y}$ \\
\hline 4340 & 472 & ST2572 & Izmit & $17 / 8 / 1999$ & 7.6 & strike slip & 93 & $\mathrm{X}$ \\
\hline 1256 & 472 & ST769 & Izmit & $17 / 8 / 1999$ & 7.6 & strike slip & 92 & $\mathrm{X}$ \\
\hline 153 & 67 & ST37 & Caldiran & $\begin{array}{c}24 / 11 / 197 \\
6\end{array}$ & 7 & strike slip & 52 & $\mathrm{y}$ \\
\hline 6918 & 472 & ST775 & Izmit & $17 / 8 / 1999$ & 7.6 & strike slip & 95 & $\mathrm{x}$ \\
\hline 1256 & 472 & ST769 & Izmit & $17 / 8 / 1999$ & 7.6 & strike slip & 92 & $\mathrm{y}$ \\
\hline 4341 & 472 & ST2573 & Izmit & $17 / 8 / 1999$ & 7.6 & strike slip & 93 & $\mathrm{y}$ \\
\hline 1248 & 472 & ST774 & Izmit & $17 / 8 / 1999$ & 7.6 & strike slip & 55 & $\mathrm{X}$ \\
\hline
\end{tabular}

\section{References}

Abrahamson N, Atkinson G, Boore D, Bozorgnia Y, Campbell K, Chiou B, Idriss IM, Silva W, Youngs R (2008) Comparisons of the NGA ground-motion relations. Earthquake Spectra 24 (1):45-66

Anderson JG (2014) The composite source model for broadband simulations of strong ground motions. Seismological Research Letters 86 (1):68-74

ASCE (2010) Minimum Design Loads for Buildings and Other Structures, ASCE 7-10. American Society of Civil Engineers (ASCE), Reston, Virginia

ASCE (2016) Minimum Design Loads for Buildings and Other Structures, ASCE 7-16 ASCE, Reston, Virginia

Atkinson GM, Silva W (2000) Stochastic modeling of California ground motions. Bulletin of the Seismological Society of America 90 (2):255-274

Beck JL, Papadimitriou C (1993) Moving resonance in nonlinear response to fully nonstationary stochastic ground motion. Probabilistic Engineering Mechanics 8 (3-4):157-167. doi:http://dx.doi.org/10.1016/0266-8920(93)90011-J

Boore DM (2003) Simulation of ground motion using the stochastic method. Pure and Applied Geophysics 160:635-676

Bradley BA (2010) A generalized conditional intensity measure approach and holistic ground-motion selection. Earthquake Engineering \& Structural Dynamics 39 (12):1321-1342

CEN (2004) Eurocode 8: Design Provisions for Earthquake Resistance Of Structures, Part 1.1: General Rules, Seismic Actions And Rules For Buildings. Pren1998-1,

Chiou B, Darragh R, Gregor N, Silva W (2008) NGA project strong-motion database. Earthquake Spectra 24 (1):23-44

Deniz D, Song J, Hajjar JF (2017) Energy-based seismic collapse criterion for ductile planar structural frames. Engineering Structures 141:1-13

FEMA-P-58 (2012) Seismic performance assessment of buildings. Applied Technology Council, Redwood City, CA 
Galasso C, Iervolino I (2011) Relevant and minor criteria in real record selection procedures based on spectral compatibility. In: Proc. 14th Conference ANIDIS “L'ingegneria sismica in Italia”, Bari (Italy).

Galasso C, Zareian F, Iervolino I, Graves R (2012) Validation of ground-motion simulations for historical events using SDoF systems. Bulletin of the Seismological Society of America 102 (6):2727-2740

Gidaris I, Taflanidis AA (2013) Parsimonious modeling of hysteretic structural response in earthquake engineering: Calibration/validation and implementation in probabilistic risk assessment. Engineering Structures 49:1017-1033

Gidaris I, Taflanidis AA (2015) Performance assessment and optimization of fluid viscous dampers through life-cycle cost criteria and comparison to alternative design approaches. Bulletin of Earthquake Engineering 13 (4):1003-1028

Goulet CA, Haselton CB, Mitrani-Reiser J, Beck JL, Deierlein G, Porter KA, Stewart JP (2007) Evaluation of the seismic performance of code-conforming reinforced-concrete frame building-From seismic hazard to collapse safety and economic losses. Earthquake Engineering and Structural Dynamics 36 (13):1973-1997

Graves R, Jordan TH, Callaghan S, Deelman E, Field E, Juve G, Kesselman C, Maechling P, Mehta G, Milner K (2011) CyberShake: A physics-based seismic hazard model for southern California. Pure and Applied Geophysics 168 (3-4):367-381

Graves RW, Pitarka A (2010) Broadband ground-motion simulation using a hybrid approach. Bulletin of the Seismological Society of America 100 (5A):2095-2123

Iervolino I, De Luca F, Cosenza E (2010a) Spectral shape-based assessment of SDOF nonlinear response to real, adjusted and artificial accelerograms. Engineering Structures 32 (9):27762792

Iervolino I, Galasso C, Cosenza E (2010b) REXEL: computer aided record selection for code-based seismic structural analysis. Bulletin of Earthquake Engineering 8 (2):339-362

Kaklamanos J, Baise LG, Boore DM (2011) Estimating unknown input parameters when implementing the NGA ground-motion prediction equations in engineering practice Earthquake Spectra 27 (4):1219-1235

Katsanos E, Sextos A (2015) Inelastic spectra to predict period elongation of structures under earthquake loading. Earthquake Engineering \& Structural Dynamics 44 (11):1765-1782

Katsanos E, Sextos A (2018) Structure-specific selection of earthquake ground motions for the reliable design and assessment of structures. Bulletin of Earthquake Engineering 16 (2):583611

Katsanos EI, Sextos AG, Manolis GD (2010) Selection of earthquake ground motion records: A stateof-the-art review from a structural engineering perspective. Soil Dynamics and Earthquake Engineering 30 (4):157-169

Kohrangi M, Bazzurro P, Vamvatsikos D, Spillatura A (2017) Conditional spectrum-based ground motion record selection using average spectral acceleration. Earthquake Engineering \& Structural Dynamics

Lin T, Haselton CB, Baker JW (2013) Conditional spectrum-based ground motion selection. Part I: Hazard consistency for risk-based assessments. Earthquake Engineering and Structural Dynamics 42 (12): 1847-1865

Mathworks (2018) SIMULINK: User's Guide.

Mavroeidis GP, Scotti CM (2013) Finite-fault simulation of strong ground motion from the $2010 M_{w}$ 7.0 Haiti earthquake. Bulletin of the Seismological Society of America 103 (5):2557-2576

Moehle J, Deierlein G (2004) A framework methodology for performance-based earthquake engineering. In: 13th World Conference on Earthquake Engineering, Vancouver, Canada, August 1-6.

Power M, Chiou B, Abrahamson N, Bozorgnia Y, Shantz T, Roblee C (2008) An overview of the NGA project. Earthquake Spectra 24 (1):3-21 
Reyes JC, Kalkan E (2012) How many records should be used in an ASCE/SEI-7 ground motion scaling procedure? Earthquake Spectra 28 (3):1223-1242

Rezaeian S, Der Kiureghian A (2010) Simulation of synthetic ground motions for specified earthquake and site characteristics. Earthquake Engineering \& Structural Dynamics 39 (10): $1155-1180$

Ruiz-García J, Miranda E (2003) Inelastic displacement ratios for evaluation of existing structures. Earthquake Engineering \& Structural Dynamics 32 (8):1237-1258

Scherbaum F, Cotton F, Staedtke H (2006) The estimation of minimum-misfit stochastic models from empirical ground-motion prediction equations. Bulletin of the Seismological Society of America 96 (2):427-445

Seifried A, Baker J (2016) Spectral variability and its relationship to structural response estimated from scaled and spectrum-matched ground motions. Earthquake Spectra 32 (4):2191-2205

Smerzini C, Galasso C, Iervolino I, Paolucci R (2014) Ground motion record selection based on broadband spectral compatibility. Earthquake Spectra 30 (4):1427-1448

Tsioulou A, Taflanidis AA, Galasso C (2018a) Modification of stochastic ground motion models for matching target intensity measures. Earthquake Engineering \& Structural Dynamics 47 (1):324

Tsioulou A, Taflanidis AA, Galasso C (2018b) Hazard-compatible modification of stochastic ground motion models. Earthquake Engineering \& Structural Dynamics 47 (8):1774-1798

Vetter C, Taflanidis A (2014) Comparison of alternative stochastic ground motion models for seismic risk characterization. Soil Dynamics and Earthquake Engineering 58:48-65

Vetter C, Taflanidis AA, Mavroeidis GP (2016) Tuning of stochastic ground motion models for compatibility with ground motion prediction equations. Earthquake Engineering and Structural Dynamics 45 (6):893-912

Vlachos C, Papakonstantinou KG, Deodatis G (2018) Predictive model for site specific simulation of ground motions based on earthquake scenarios. Earthquake Engineering \& Structural Dynamics 47 (1):195-218 


\section{Figures}
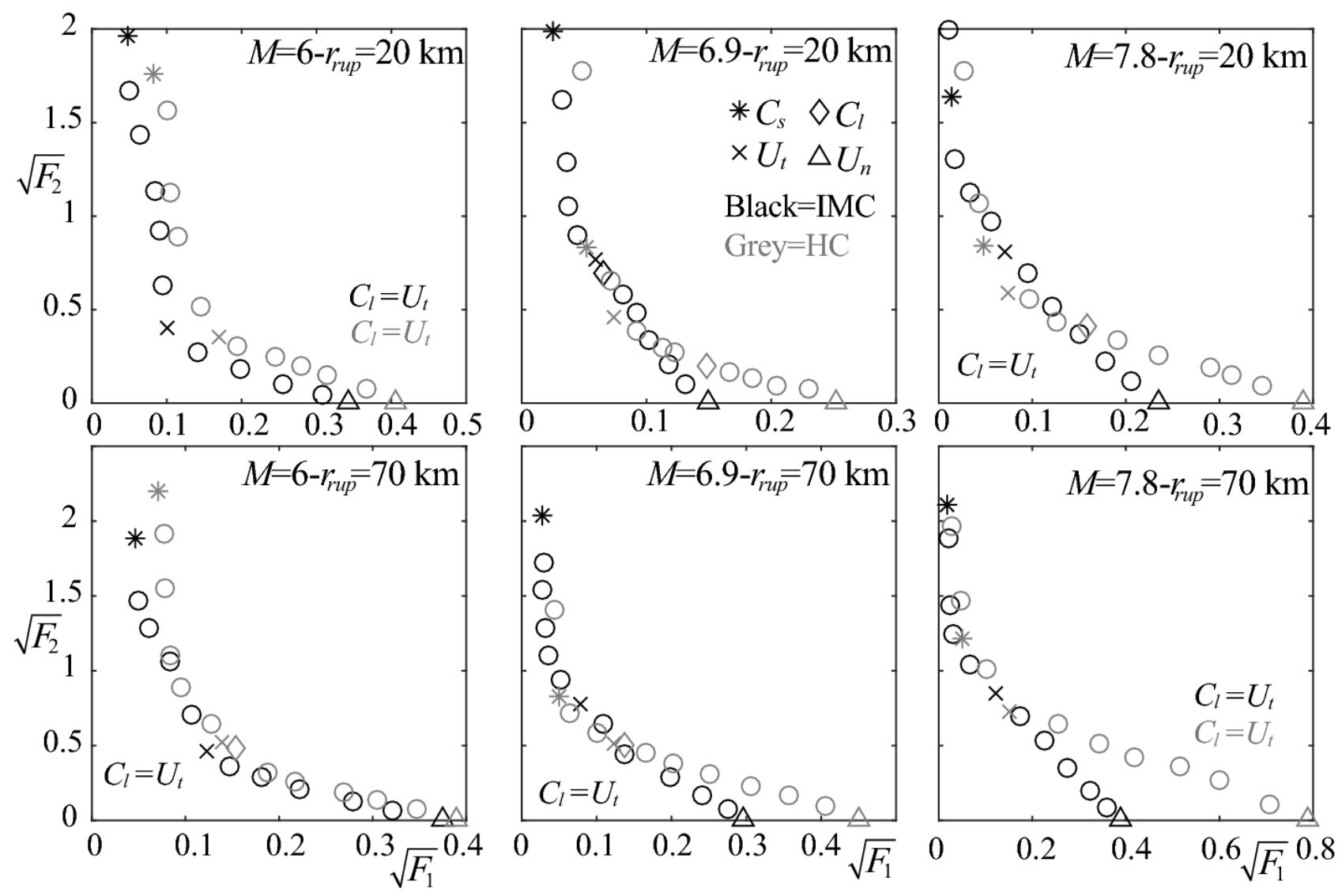

Fig 1 Pareto fronts for the stochastic ground motion modification for IMC (black) and HC (gray)
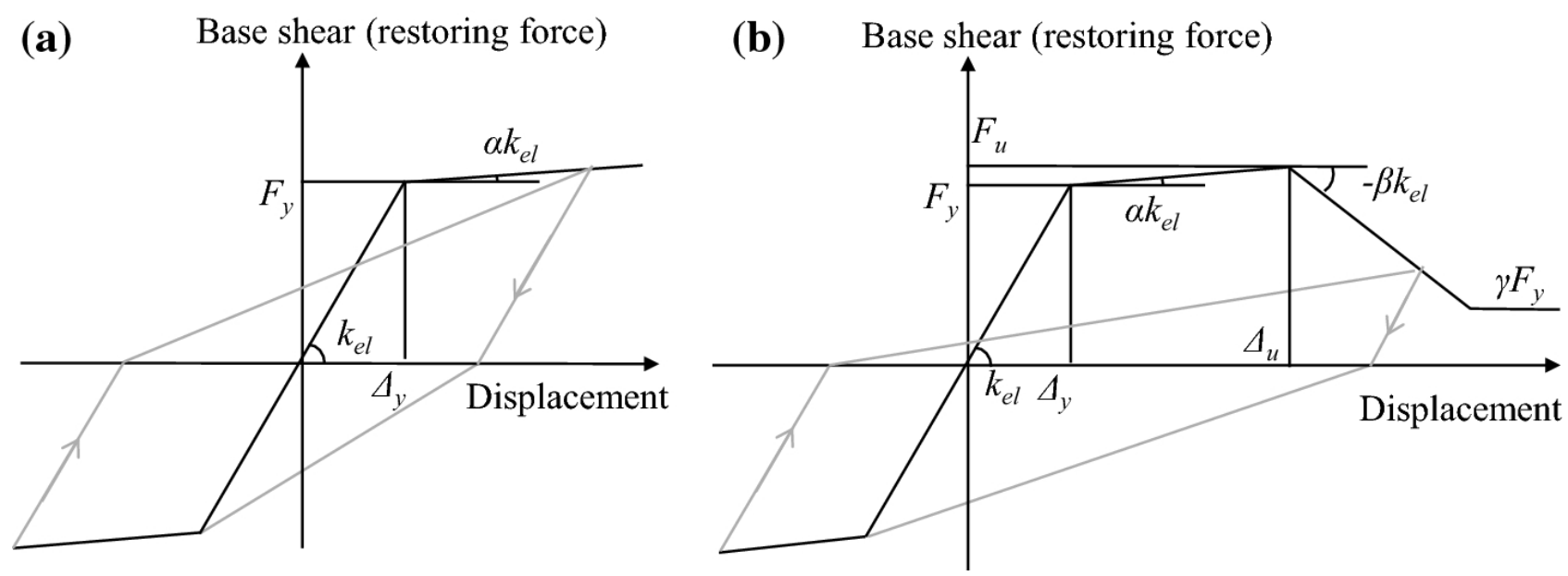

Fig 2 Hysteretic behavior model for (a) EPH system and (b) ESD system 

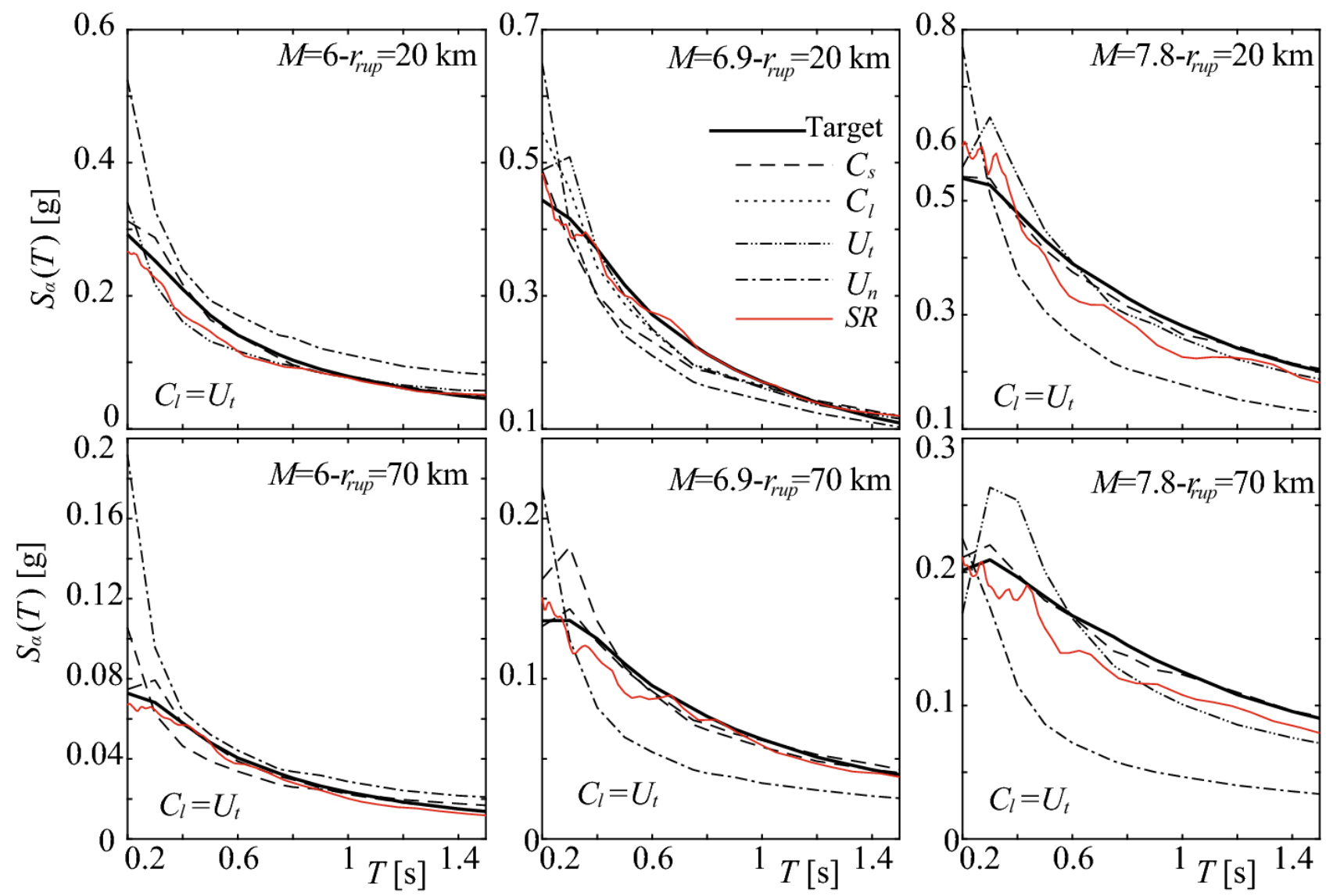

Fig 3 Spectral plot comparison of target spectra and average predictions of recorded $(S R)$ and stochastic ground motions for IMC
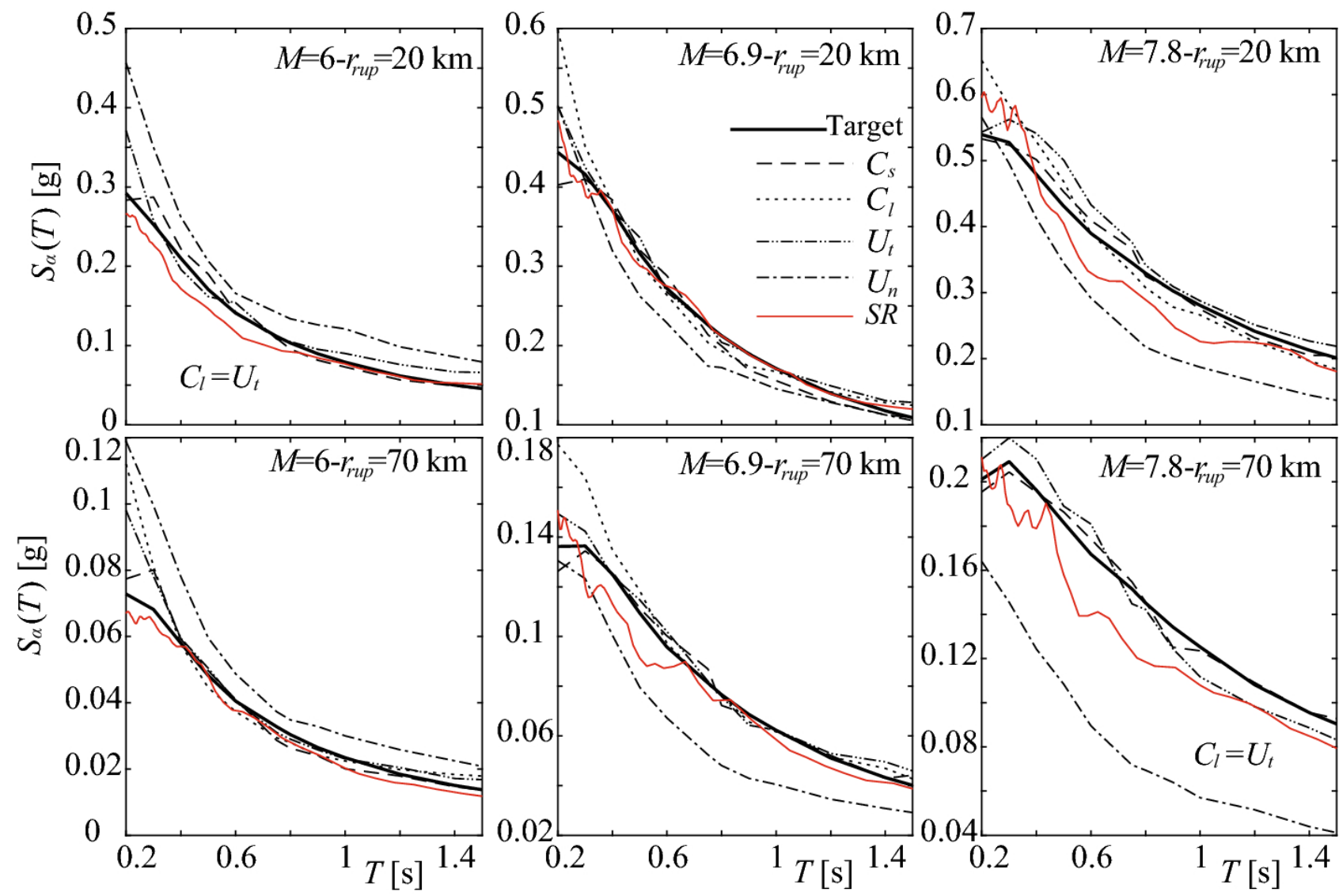

Fig 4 Spectral plot comparison of target spectra and average predictions of recorded $(S R)$ and stochastic ground motions for $\mathrm{HC}$ 


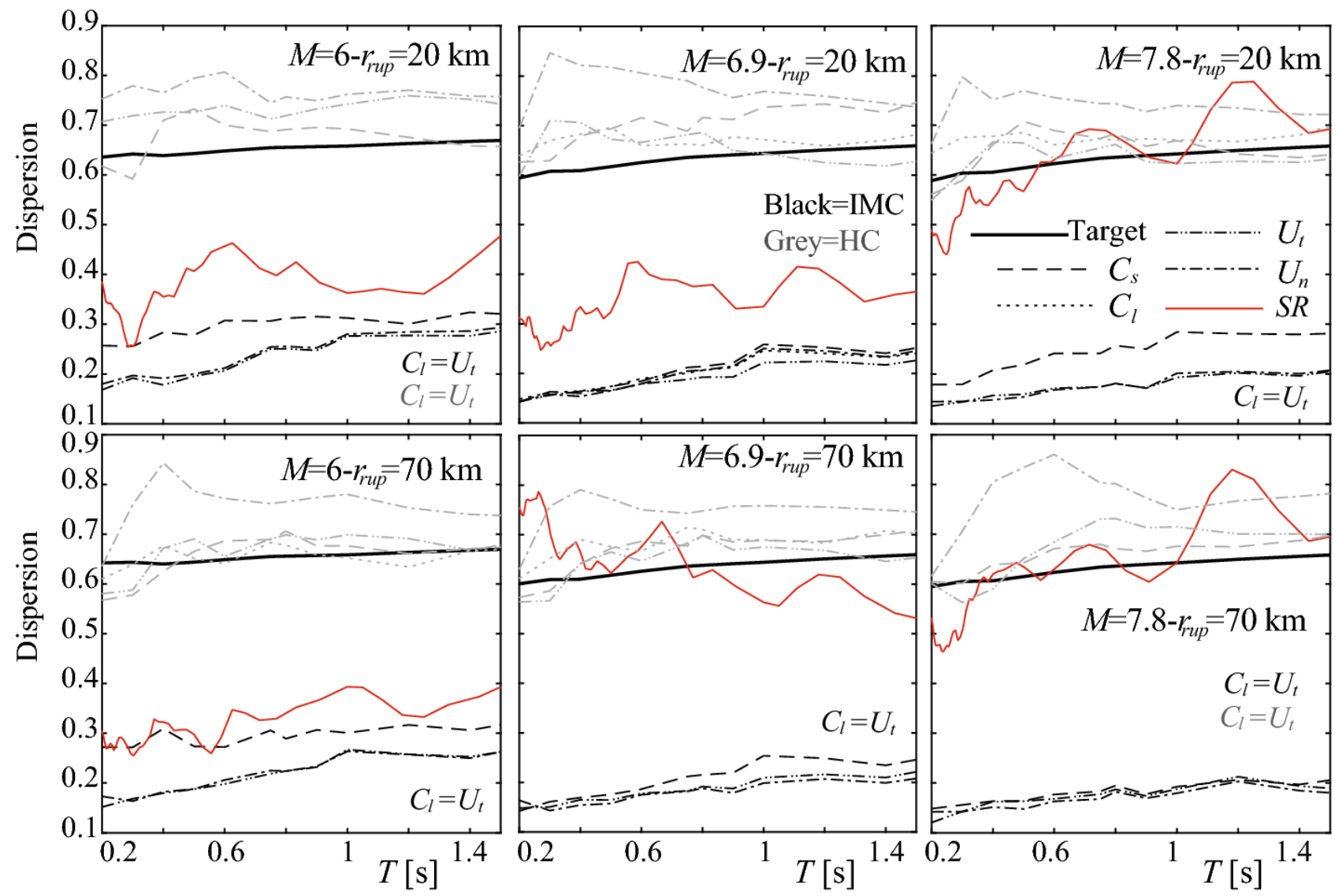

Fig 5 Comparison of dispersion of target, recorded $(S R)$ and stochastic ground motions $\left(U_{n}, U_{t}, C_{s}\right)$ for IMC and $\mathrm{HC}$

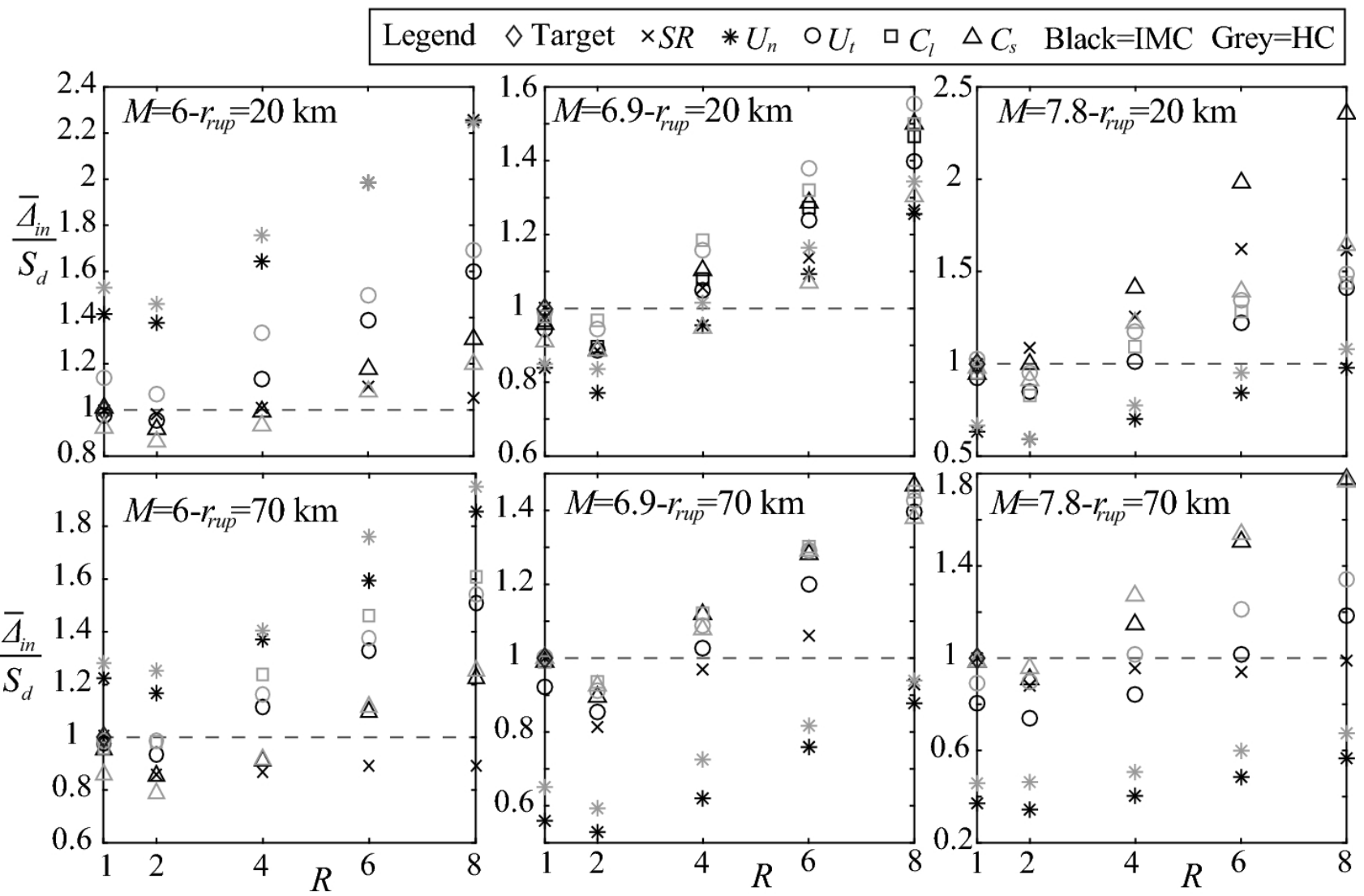

Fig 6 Normalized median peak inelastic displacements for EPH system with $\alpha=3 \%$ for "constant-R" approach 


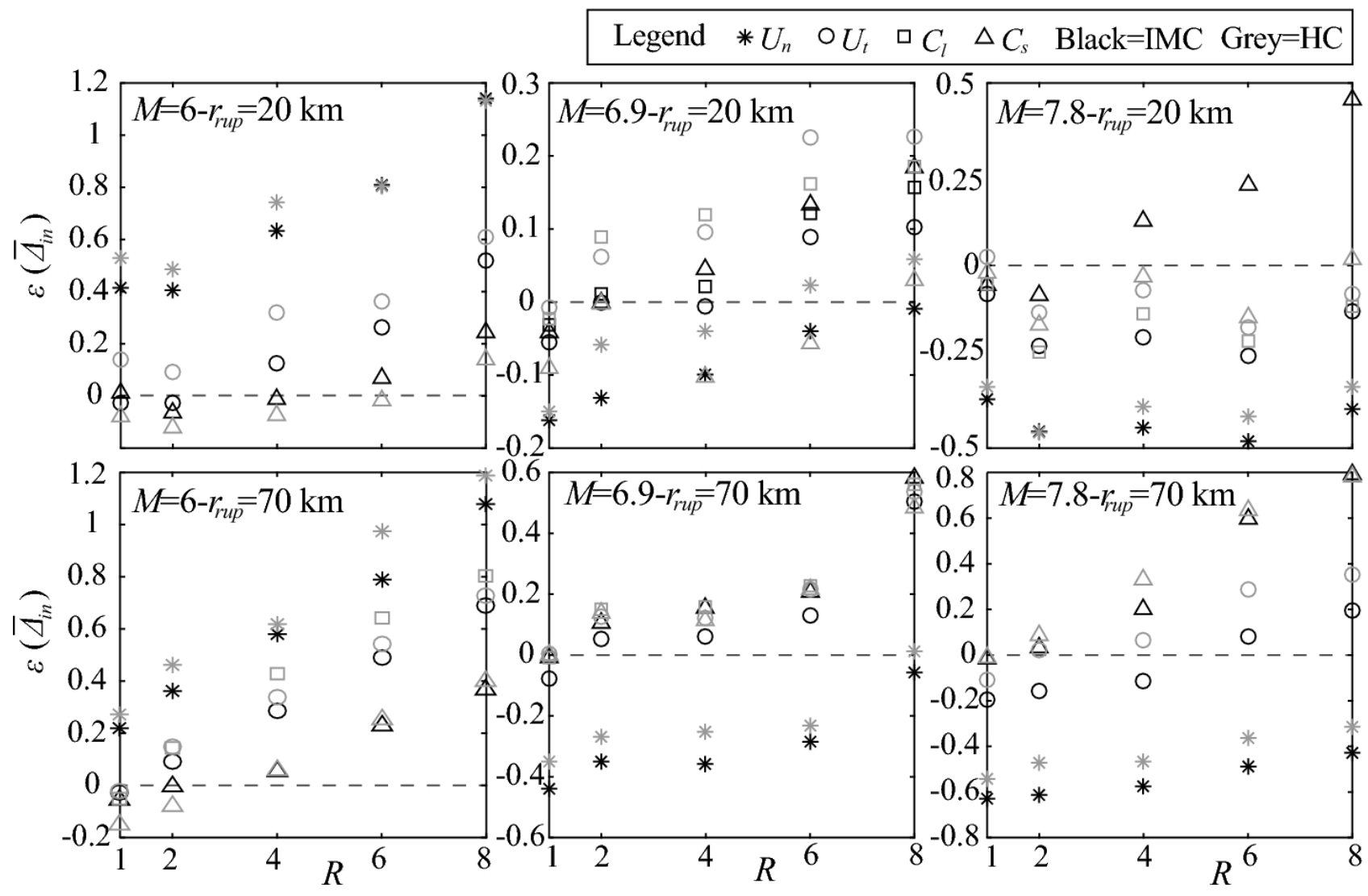

Fig 7 Relative error compared to reference $S R$ response for the peak inelastic displacements for EPH system with $\alpha=3 \%$ for "constant-R" approach

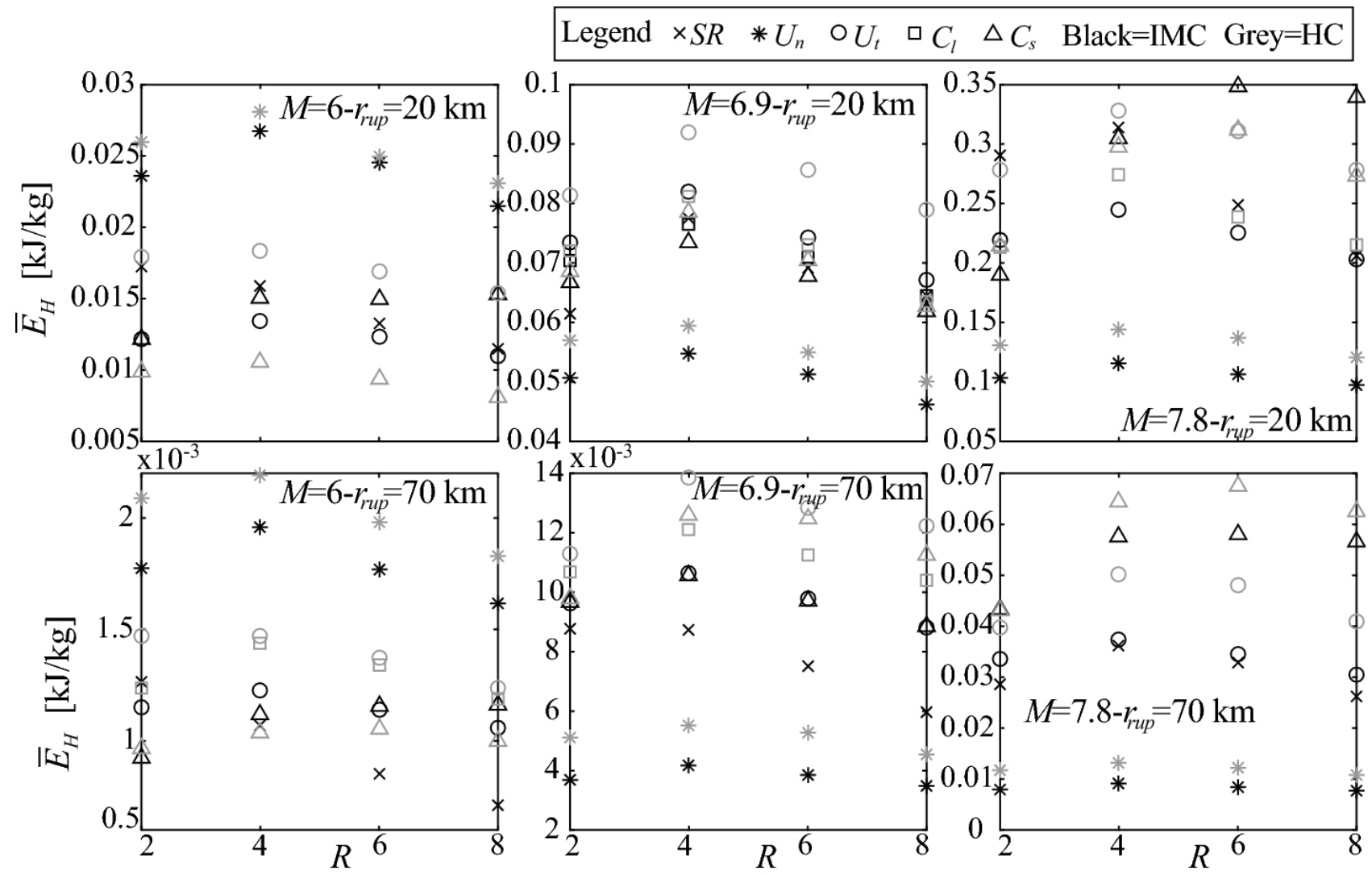

Fig 8 Median hysteretic energy for EPH system with $\alpha=3 \%$ for "constant-R" approach 
Legend $\times S R \quad * U_{n} \circ U_{t} \quad \square C \triangle C_{s} \quad$ Black=IMC Grey=HC

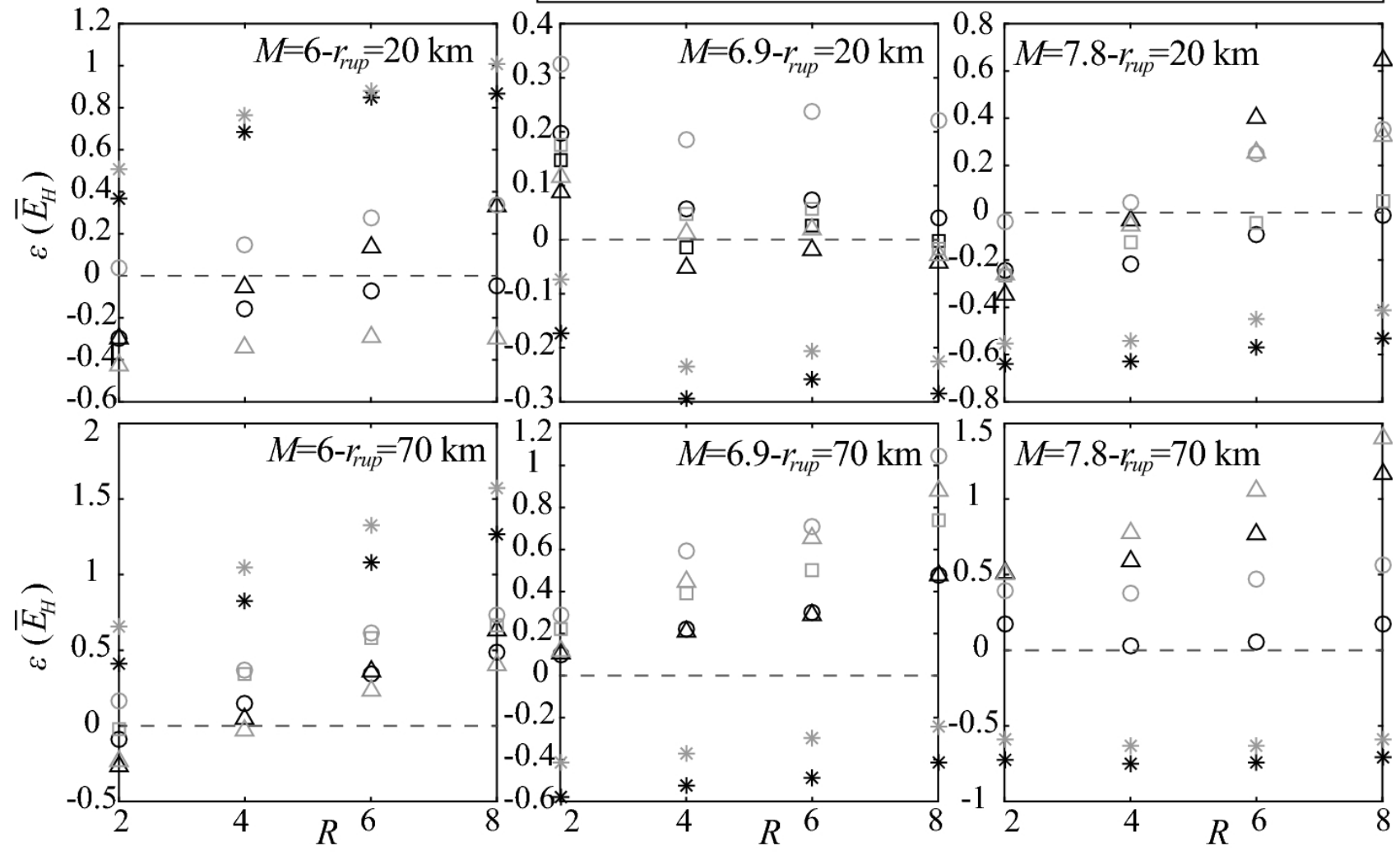

Fig 9 Relative error compared to reference $S R$ response for the hysteretic energy for EPH system with $\alpha=3 \%$ for "constant-R" approach

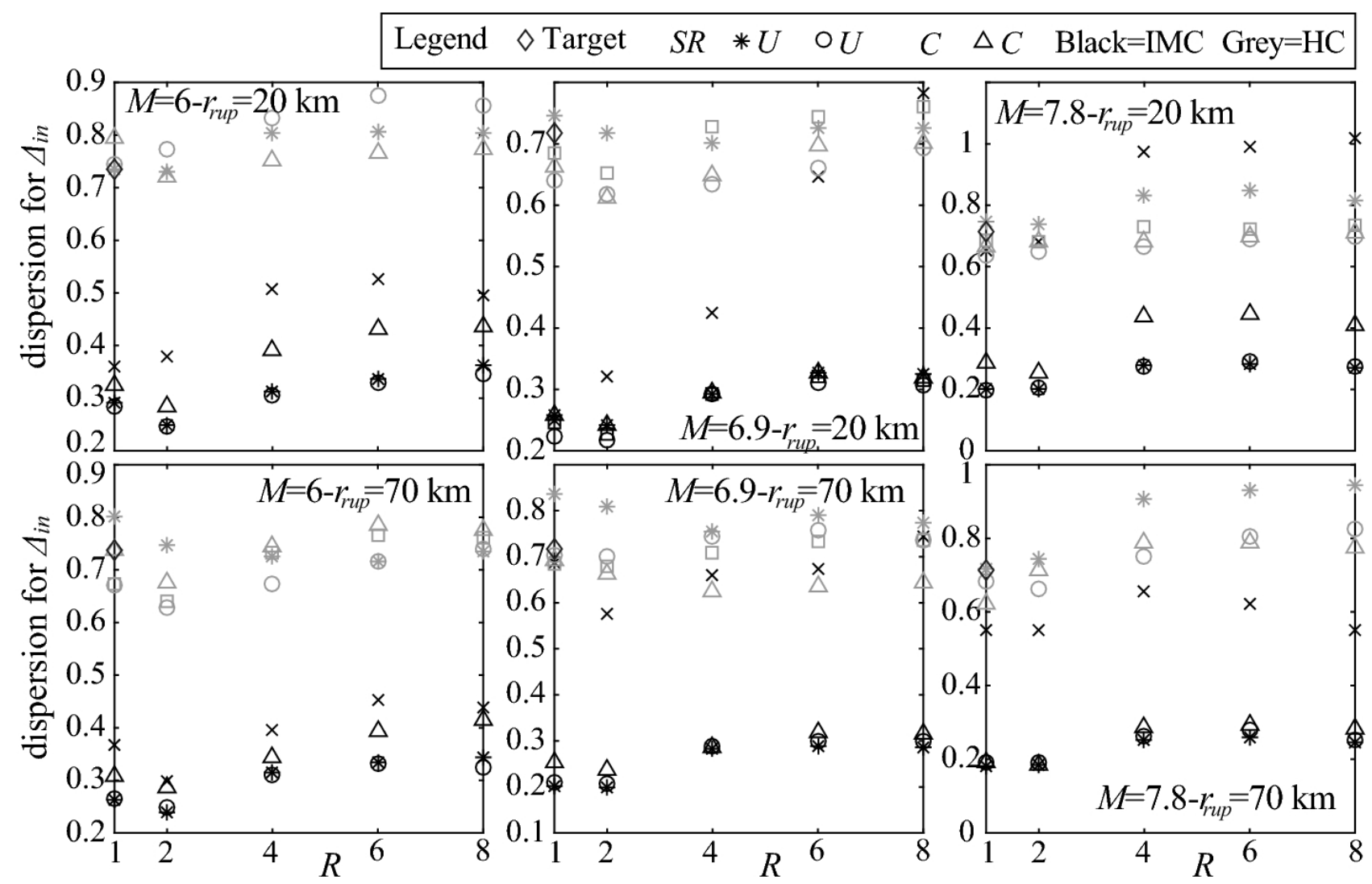

Fig 10 Dispersion (expressed through coefficient of variation) of peak inelastic displacement for EPH system with $\alpha=3 \%$ for "constant-R" approach 


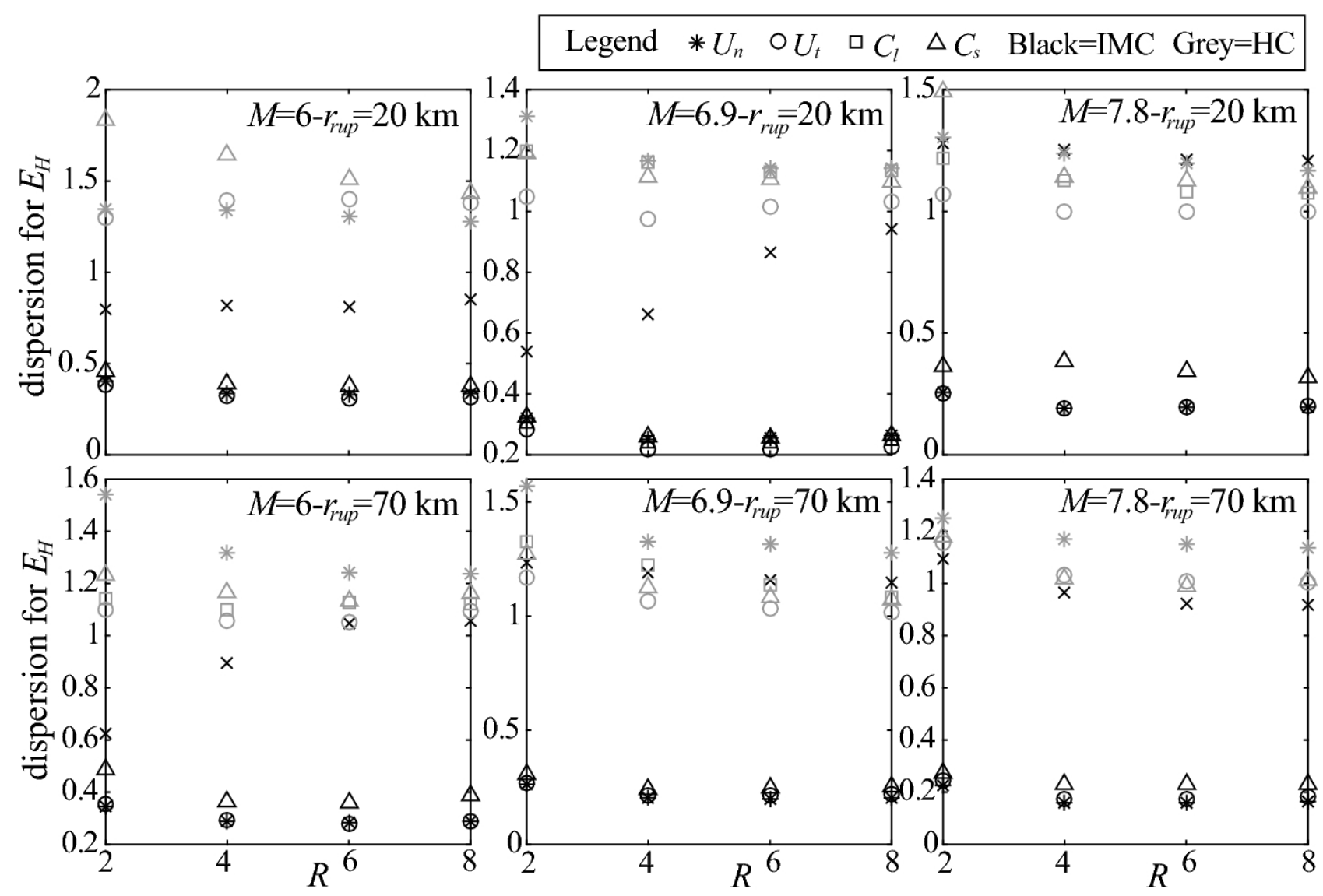

Fig 11 Dispersion (expressed through coefficient of variation) of hysteretic energy for EPH system with $\alpha=3 \%$ for "constant-R" approach

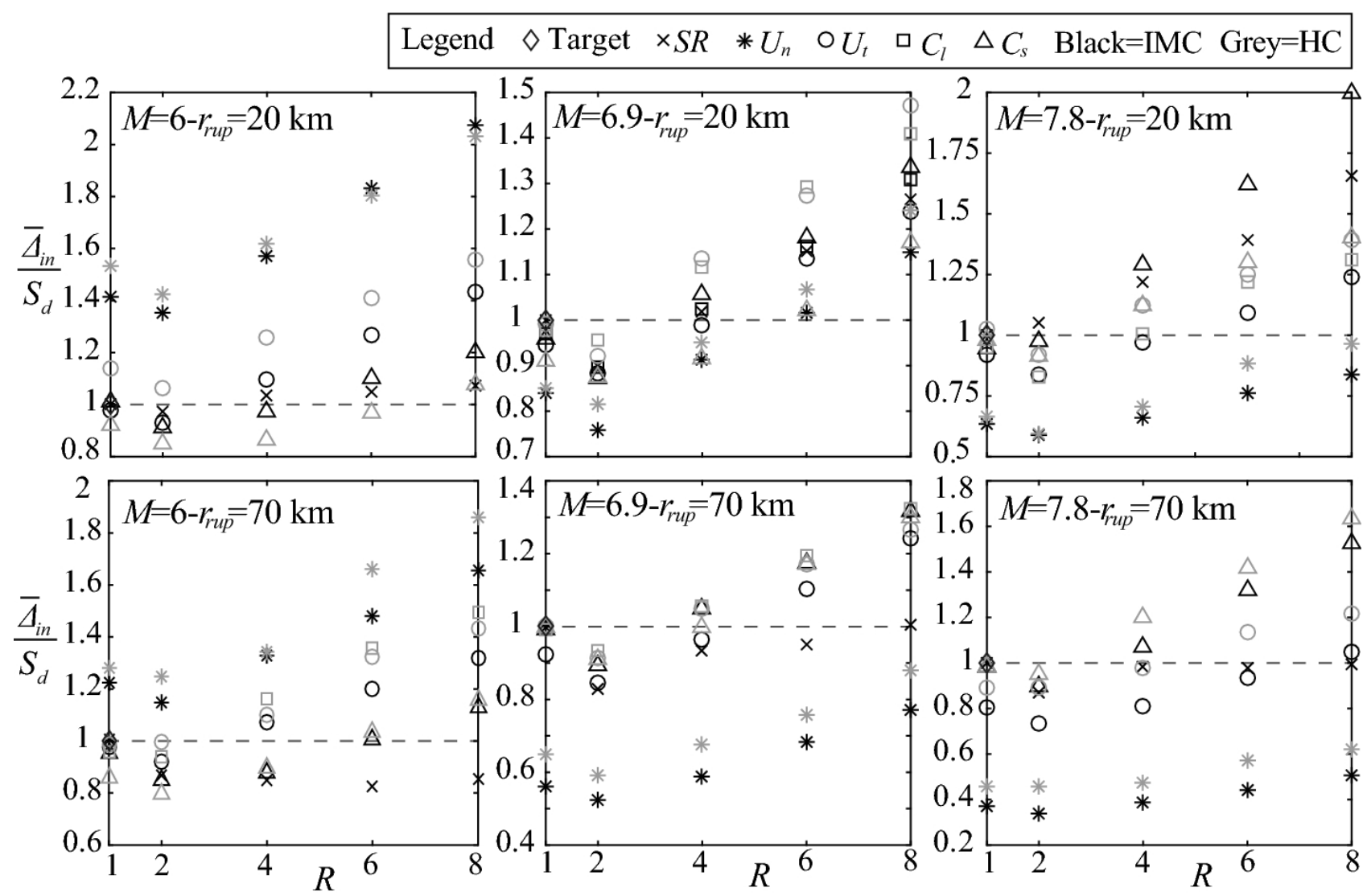

Fig 12 Normalized median peak inelastic displacements for EPH system with $\alpha=10 \%$ for "constant-R" approach 


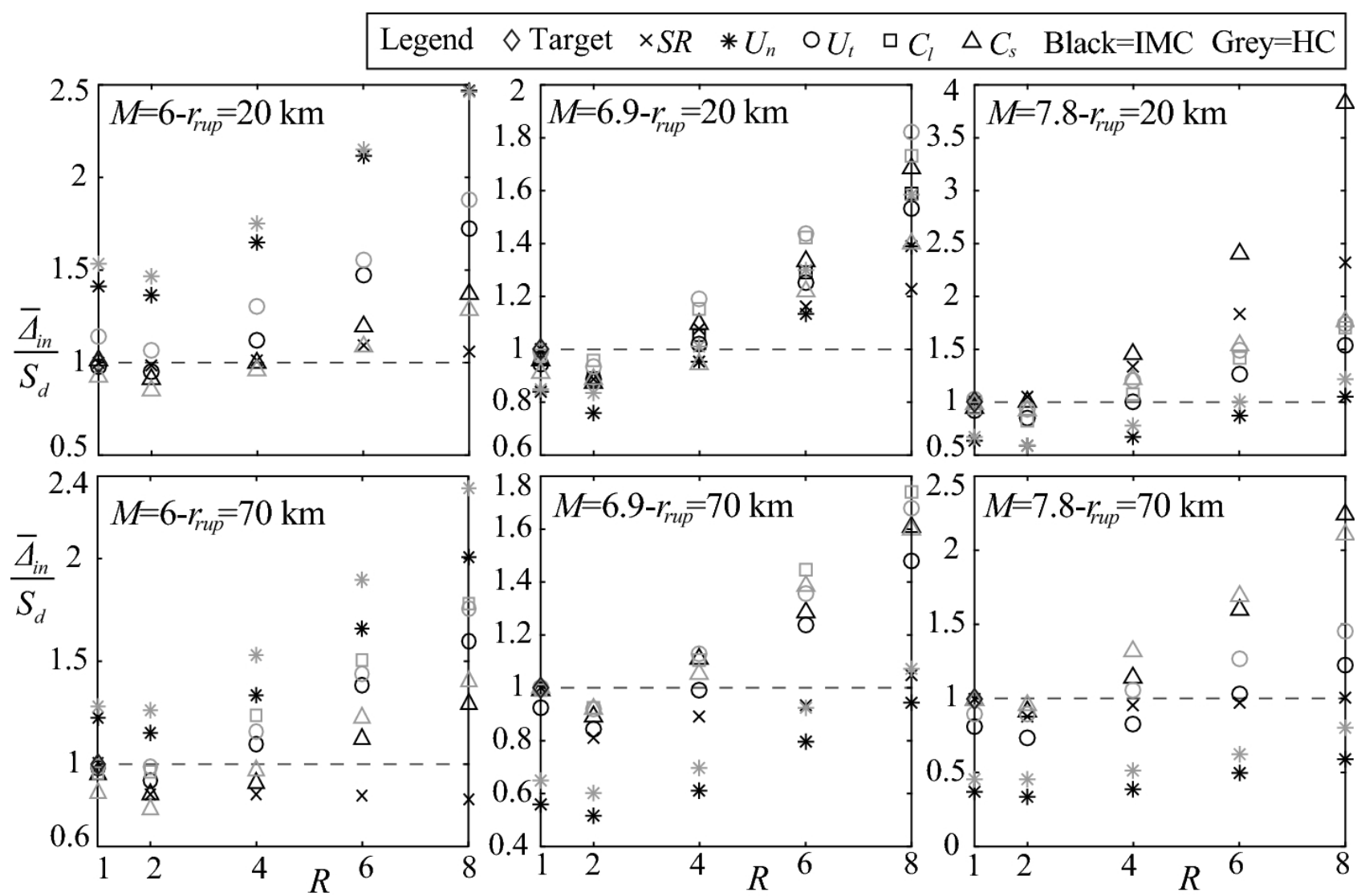

Fig 13 Normalized median peak inelastic displacements for ESD system for "constant-R" approach

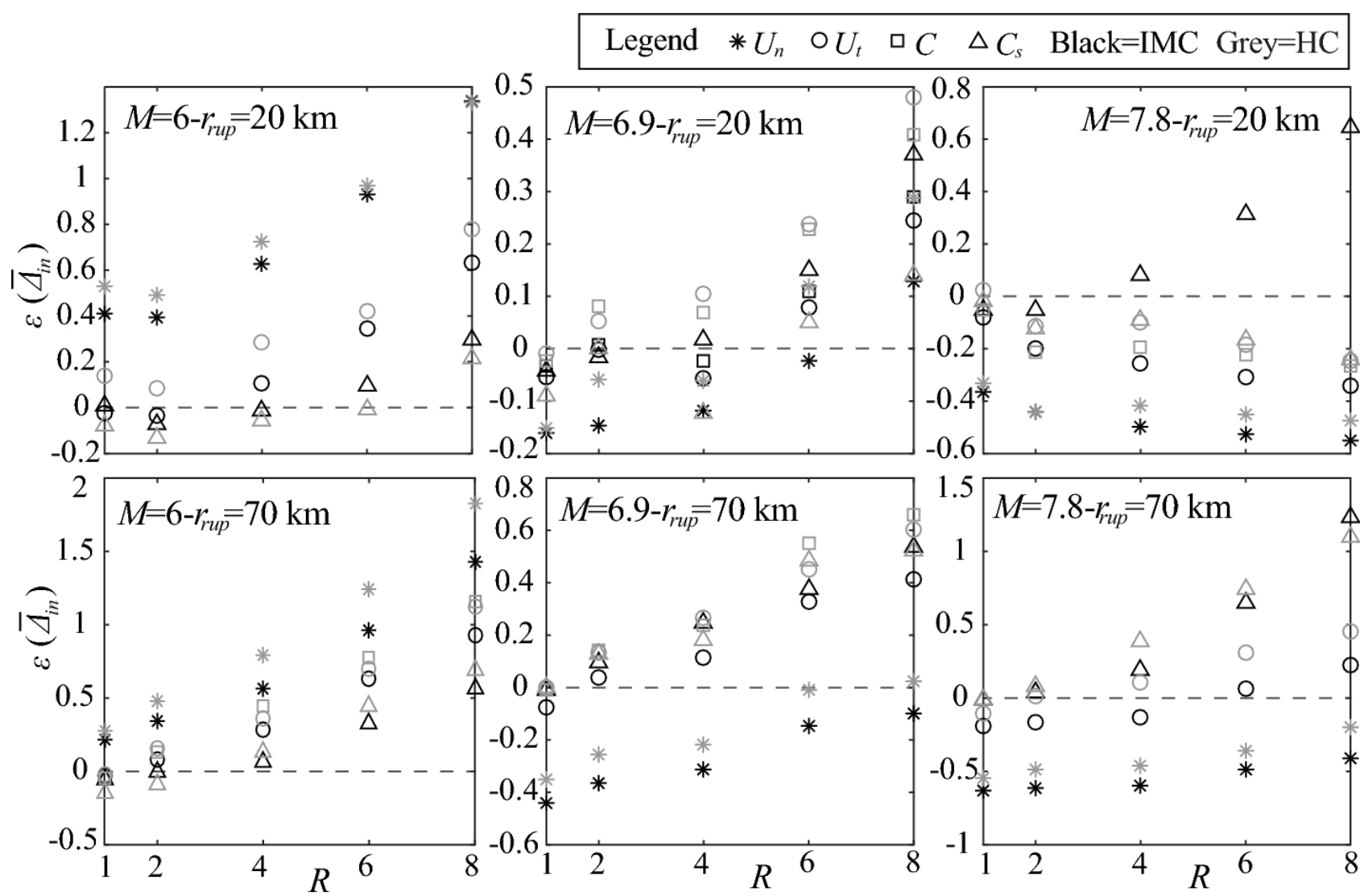

Fig 14 Relative error compared to reference $S R$ response for the peak inelastic displacements for ESD system for "constant-R" approach 


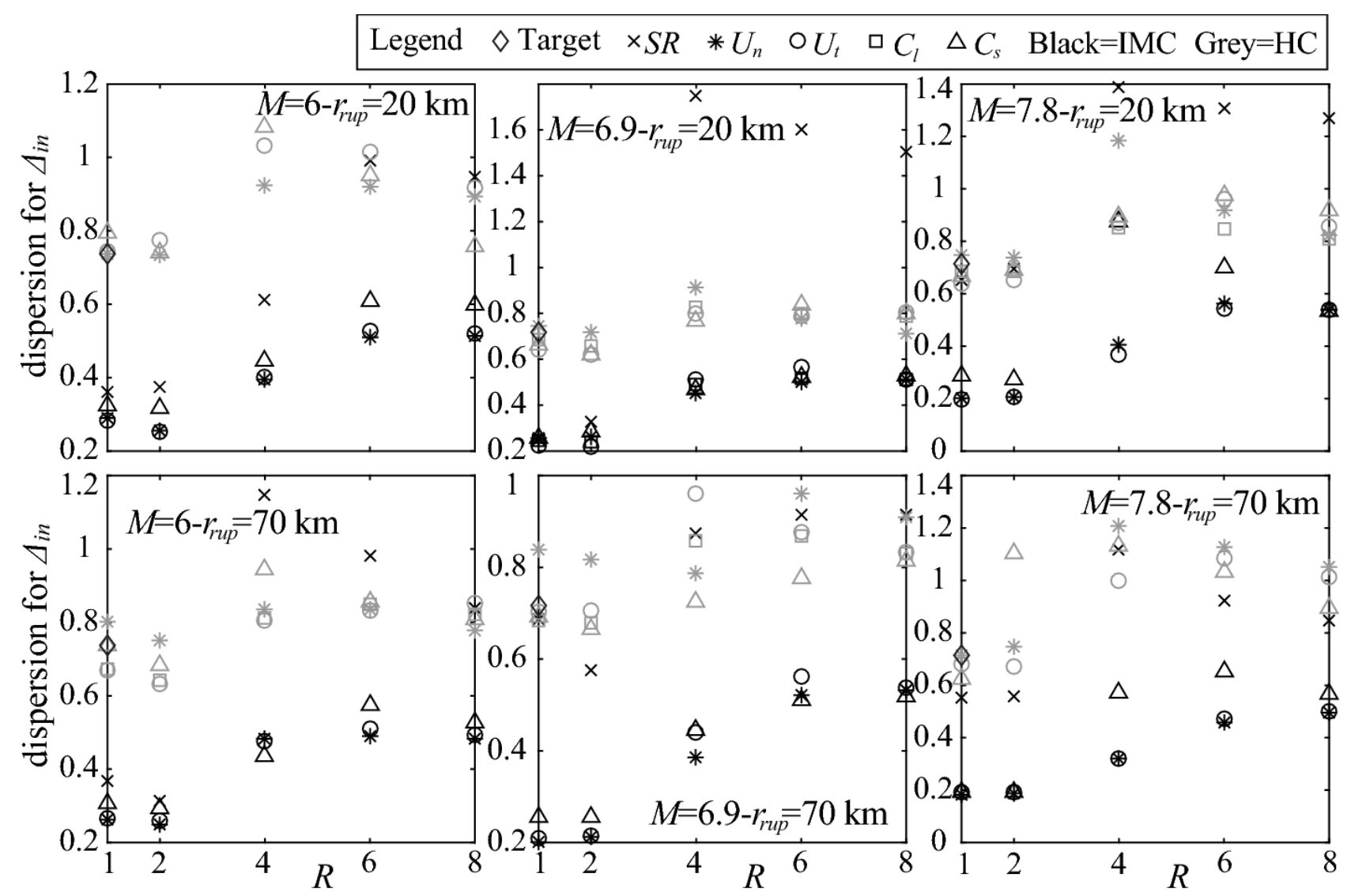

Fig 15 Dispersion (expressed through coefficient of variation) of peak inelastic displacement for ESD system for "constant-R" approach

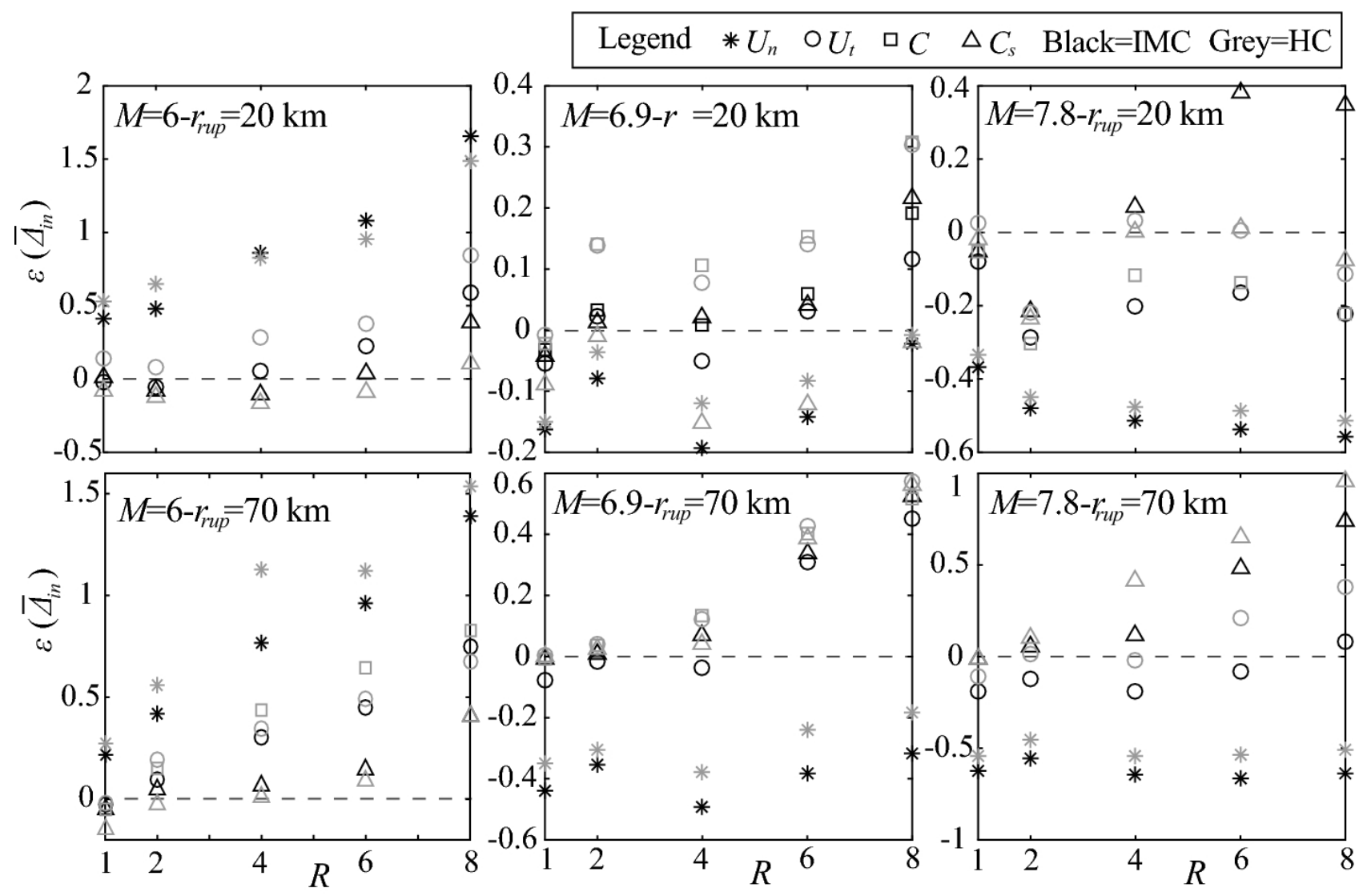

Fig 16 Relative error compared to reference $S R$ response for the peak inelastic displacements for EPH system with $\alpha=3 \%$ for "constant-strength" approach 


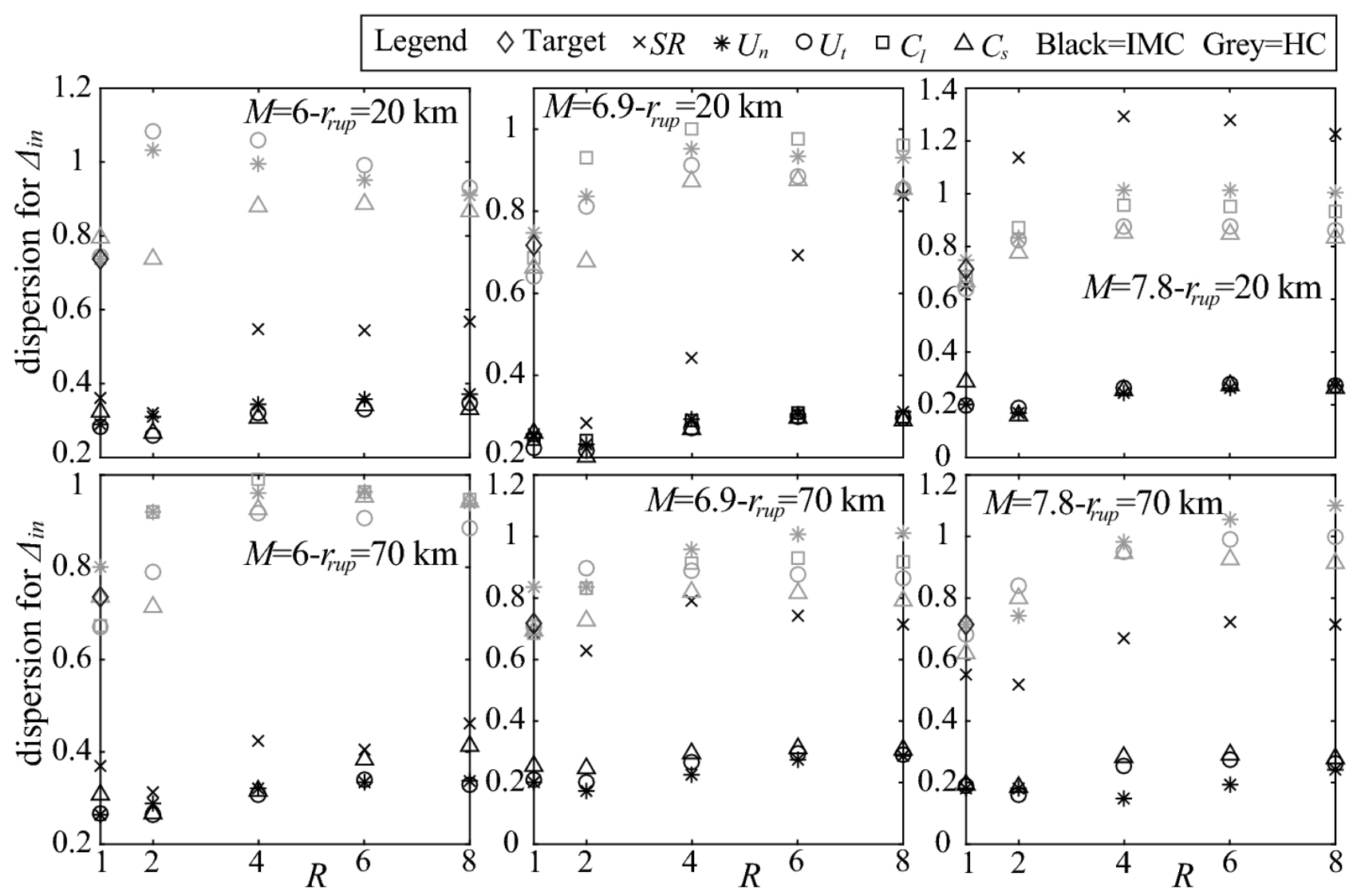

Fig 17 Dispersion (expressed though coefficient of variation) of peak inelastic displacement for EPH system with $\alpha=3 \%$ for "constant-strength" approach

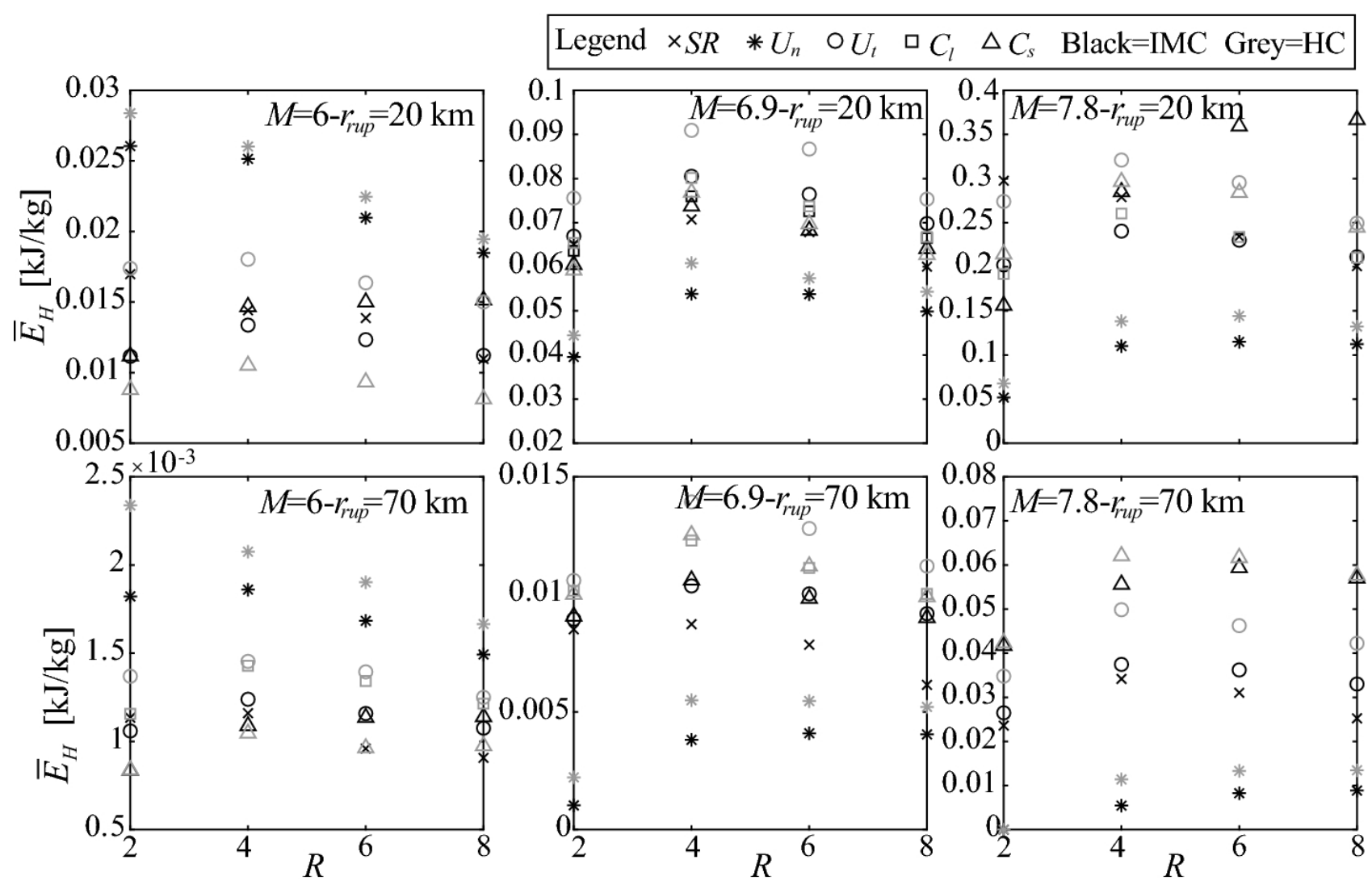

Fig 18 Median hysteretic energy for EPH system with $\alpha=3 \%$ for "constant-strength" approach 


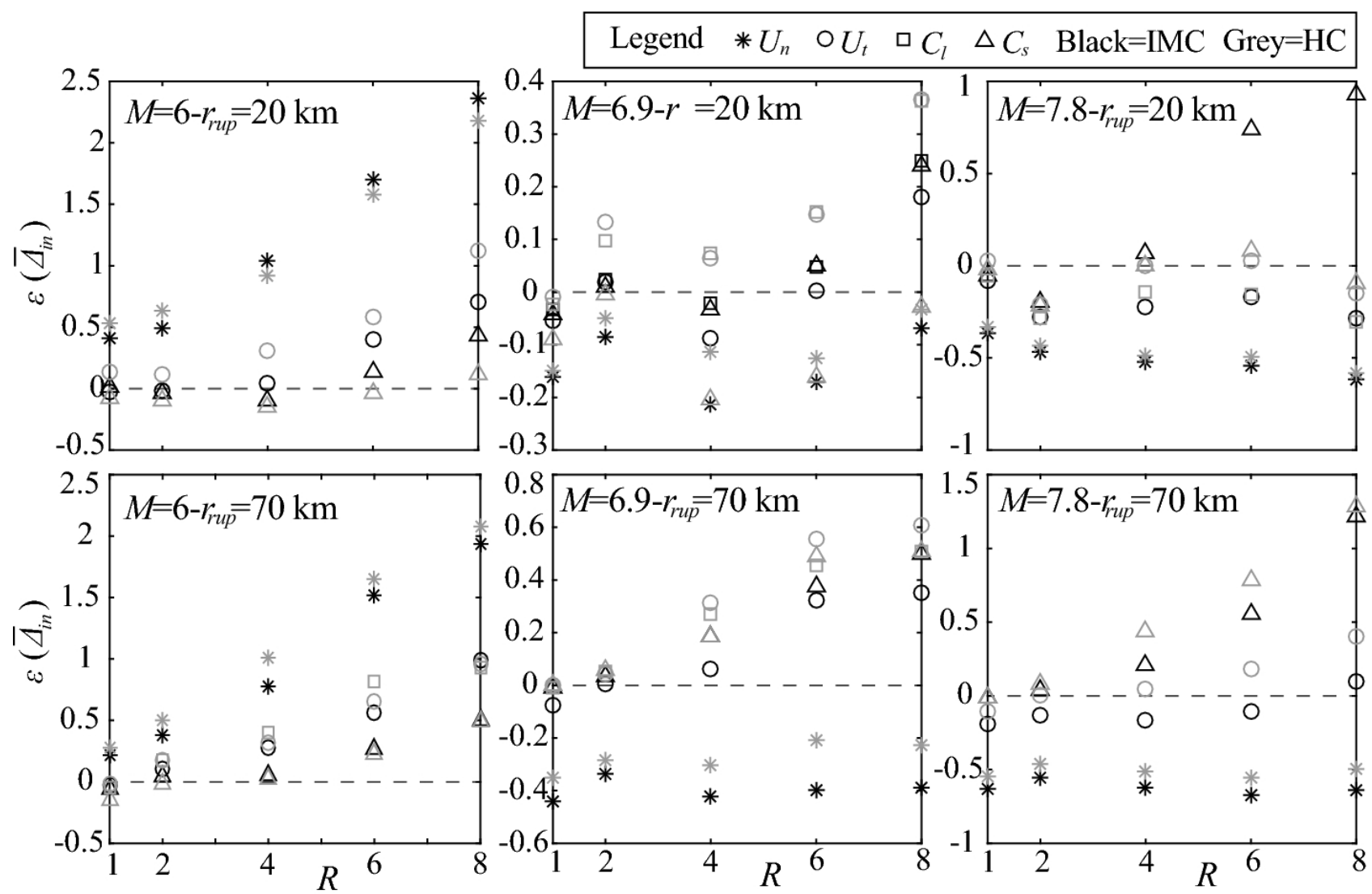

Fig 19 Relative error compared to reference $S R$ response for the peak inelastic displacements for ESD system with $\alpha=3 \%$ for "constant-strength" approach

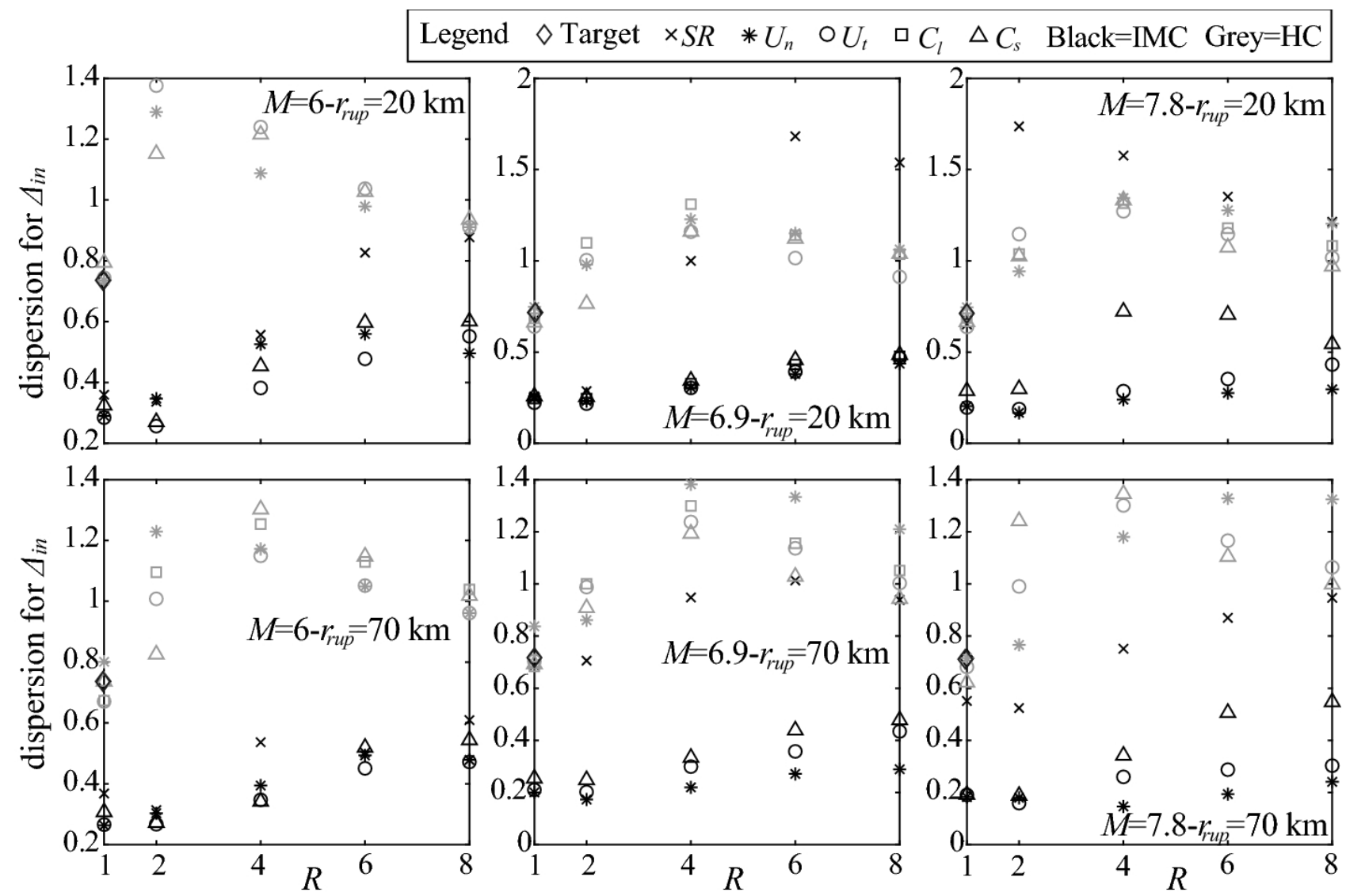

Fig 20 Dispersion (expressed though coefficient of variation) of peak inelastic displacement for ESD system with $\alpha=3 \%$ for "constant-strength" approach 


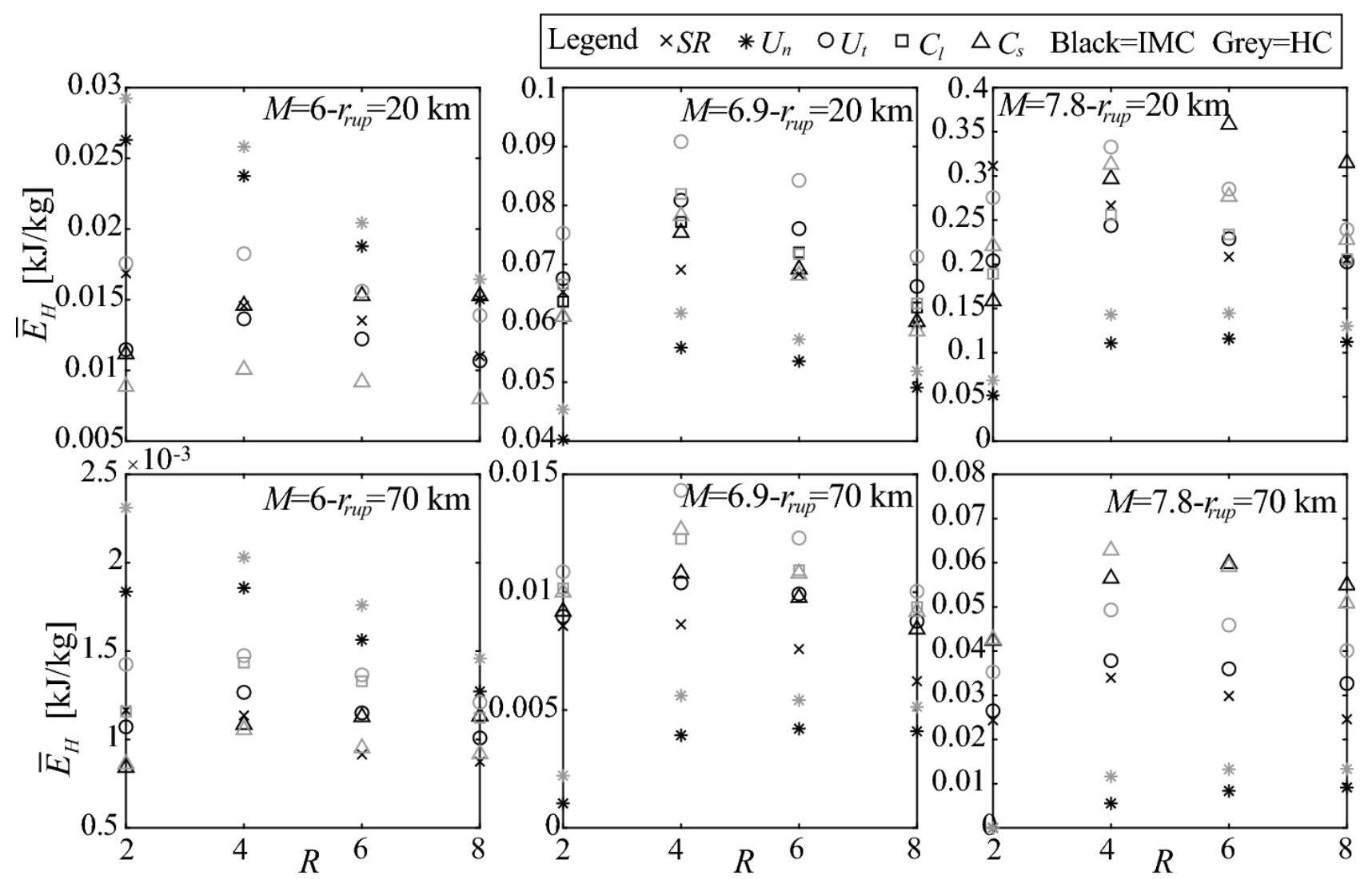

Fig 21 Median hysteretic energy for ESD system with $\alpha=3 \%$ for "constant-strength" approach 